This is the accepted manuscript version of this paper before copy-editing, formatting, technical enhancements and pagination. The finally published version (version of record) can be found via https://doi.org/10.1016/j.rse.2019.01.004

(C) 2018. This manuscript version is made available under the CC-BY-NC-ND 4.0 license https://creativecommons.org/licenses/by-nc-nd/4.0/

\title{
Investigating vegetation water dynamics and drought using Metop ASCAT over the North American Grasslands
}

\author{
Susan C. Steele-Dunne ${ }^{\mathrm{a}}$, Sebastian Hahn ${ }^{\mathrm{b}}$, Wolfgang Wagner $^{\mathrm{b}}$, Mariette \\ Vreugdenhil ${ }^{\mathrm{b}}$ \\ ${ }^{a}$ Department of Water Resources, Faculty of Civil Engineering and Geosciences, Delft \\ University of Technology (TU Delft), Stevinweg 1, 2628 CN Delft, The Netherlands \\ ${ }^{b}$ Department of Geodesy and Geoinformation, Vienna University of Technology (TU Wien), \\ 1040 Vienna, Austria
}

\begin{abstract}
In this study, we examined the ASCAT backscatter data from Metop-A from 2007-2016 to characterize spatial and temporal variability in the vegetation parameters of the TU Wien Soil Moisture Retrieval approach (TUW SMR) across the North American Grasslands. The vegetation parameters are the slope and curvature of a second order Taylor polynomial used to describe the incidence angle dependence of backscatter $\sigma^{\circ}$. A recent development allows the vegetation parameters to be determined dynamically using the local slope values within a prescribed temporal window. Seasonal, interannual and diurnal variations in the vegetation parameters were found to vary across grassland cover types, reflecting variations in soil moisture availability and growing season length. While the slope has always been considered a measure of vegetation density, our results show that curvature also contains information about vegetation. Drought events in 2011 and 2012 resulted in extensive negative $\sigma_{40}^{\circ}$ and soil moisture anomalies during the maximum biomass period. Contiguous anomalies in slope and curvature were observed where the severity and persistence of the drought were enough to impact vegetation. Observed diurnal differences in slope and curvature suggest that daily moisture transport within the vegetation influences
\end{abstract}

\footnotetext{
${ }^{*}$ Corresponding author

Email address: s.c.steele-dunne@tudelft.nl (Susan C. Steele-Dunne)
} 
the relative dominance of scattering from the vegetation and soil surface.

Keywords: Advanced Scatterometer (ASCAT);Radar Remote Sensing;

Vegetation;Soil Moisture;Drought;Grasslands.

\section{Introduction}

Following the launch of ERS-1 in 1991, several early studies identified the potential value of C-band scatterometry for global and regional vegetation monitoring [1, 2, 3. The Advanced Scatterometer (ASCAT) instrument carried by a series of Metop satellites builds on the success of the European scatterometer (ESCAT), which flew onboard the ERS-1/2 satellites from 1990 to 2011 [4, 5]. ASCAT is a real aperture radar operating at $5.255 \mathrm{GHz}$ (C-band) with VV polarization. At present, there are two ASCAT instruments in orbit, on board Metop-A (launched in October 2006) and Metop-B (launched in September 2012), operated by the European Organization for the Exploitation of Meteorological Satellites (EUMETSAT). Furthermore, plans to launch SCA on Metop$\mathrm{SG}$ in 2022 mean that the combined data record from ERS-1/2, Metop-A/B/C ASCAT and Metop-SG SCA will extend for at least 40 years [6]. C-band scatterometer data from this series of satellites can therefore be considered as a potentially valuable climate record for land surface monitoring.

Many studies have shown that backscatter data from C-band scatterometry correlates with the seasonal dynamics of vegetation growth and senescence. Frison et al. 2] analyzed three years of ERS-1 ESCAT data in a Sahel Region and used a semi-empirical backscatter model combined with an ecosystem grassland model to interpret the $\sigma_{45}^{\circ}$ observations. They concluded that, although soil contributions were large, biomass variations were apparent in $\sigma_{45}^{\circ}$. They also noted that the maximum backscatter did not coincide with either the peak in vegetation water content or green biomass, highlighting the confounding effects of soil moisture, vegetation water content and other surface characteristics on the total backscatter. Jarlan et al. 7] demonstrated that seasonal variations in total backscatter in the Sahel were dominated by the contributions of the soil 
and herbaceous vegetation component. However, it proved difficult to separate their effects using model inversion. In a subsequent study, they used a global stochastic nonlinear inversion method to map herbaceous mass production in the Sahel [8]. Results were consistent with NDVI observations. One limitation of this approach was that the the soil moisture content needed to be calculated a priori and the herbaceous mass estimates were sensitive to errors in the assumed soil moisture. Zine et al. 9] found that the limited herbaceous mass in agro-pastoral sites (a mixture of cultivated fields, fallow fields and natural vegetation) made soil moisture retrieval in these areas easier than in pastoral areas. Woodhouse and Hoekman [10] used a mixed target model to demonstrate the applicability of using the ERS-1 WS data to monitor vegetation dynamics and soil moisture in the Sahel. The seasonality in fractional cover was consistent with NDVI observations, and the expected lag between reflectivity (soil moisture) and vegetation peaks was detected. A subsequent application in Spain found that while soil moisture retrieval might be possible, the ability to retrieve vegetation cover parameters was highly site-specific [11. A recent comparison of backscatter signatures from altimetry and scatterometry over West Africa re-affirms the suitability of side-looking scatterometers for sensing vegetation dynamics [12. However, the challenge of disentangling soil and vegetation effects remains.

Recent studies have indicated that C-band scatterometry could be useful for detecting the onset of water stress or drought. Friesen et al. [13] identified differences between the morning and evening $\sigma_{40}^{\circ}$ overpasses of ERS-1/2 ESCAT. Friesen subsequently used hydrological modeling to argue that the largest differences found between morning and evening $\sigma_{40}^{\circ}$ in West Africa coincided with the start of the dry season and the onset of stress [14]. Schroeder et al. [15] showed that negative anomalies in $\sigma_{54}^{\circ}$ from ASCAT on Metop-A were spatially and temporally consistent with patterns of drought severity from the U.S. Drought Monitor during the 2011 and 2012 droughts. Both studies identified differences between observations collected during the descending and ascending passes. Similar differences in backscatter have also recently been detected at 
higher frequencies and attributed to vegetation water dynamics [16, 17.

The current study is motivated by recent developments in the TU Wien Soil Moisture Retrieval (TUW SMR) approach which offer a new perspective on vegetation dynamics using the ASCAT backscatter data record. A recent algorithmic development allows for the estimation of so-called "vegetation parameters" on a daily basis. The vegetation parameters are the slope and curvature of a second order Taylor polynomial used to describe the incidence angle dependence of $\sigma^{\circ}$. Until recently, the entire data record was used to generate climatological values of the parameters used to account for vegetation [18. A new approach proposed by Melzer et al. [19] determines the slope and curvature dynamically using the local slope values within a prescribed temporal window. This is significant because it allows the TUW SMR to take interannual variations in vegetation into account in the soil moisture retrieval. It has recently been shown that dynamic vegetation parameters also benefit estimates of vegetation optical depth (VOD), which have been validated against Leaf Area Index and used to assess interannual variability in vegetation dynamics [20]

While the studies above used backscatter itself, this study explores the potential value of the time series of slope and curvature as a source of information about vegetation phenology and canopy water dynamics including sub-daily variations. The first 10 years of the ASCAT backscatter data record (from Metop-A) are used to generate a time series of slope and curvature for a domain that spans the North American Grasslands. This land cover type is associated with the largest annual variations in slope, i.e. backscatter values over grasslands exhibit a huge change in sensitivity to soil moisture and vegetation during the year. The seasonal cycles of the parameters calculated from the descending overpasses, ascending overpasses and the combination of both overpasses are analyzed to determine the extent to which they reflect vegetation and soil dynamics. Interannual variability is assessed by comparing anomalies in the parameter values to drought severity indices from the same period. 


\section{TU Wien Soil Moisture Retrieval Approach}

The TUW SMR approach is used to generate several satellite-derived soil moisture products from ASCAT backscatter observations. This change detection approach was first developed for ERS-1/2 data [21, 22] and was used to generate the first global multi-year soil moisture dataset from remote sensing 23. Bartalis et al. 24] used the ERS long-term parameter database with the first ASCAT backscatter observations to demonstrate that the TUW SMR could be applied to ASCAT observations as well. Naeimi et al. [18 introduced several algorithmic improvements, addressing the vegetation and azimuthal effects in particular. The resultant WARP5 software implementation of TUW SMR forms the basis of the operationally used algorithm to produce the soil moisture products generated, distributed by and archived by the EUMETSAT Satellite Application Facility on Support to Operational Hydrology and Water Management (H SAF). The combined ERS and ASCAT soil moisture products constitute one of the longest global soil moisture datasets. These data are essential for numerical weather prediction, natural hazard monitoring and mitigation, water management and agricultural applications [5, 25, 26. They are also a key component of the European Space Agency Climate Change Initiative (ESA CCI) soil moisture product [27].

A year long time series of backscatter coefficient is shown in Figure 1(a) to illustrate the TUW SMR approach. The backscattering coefficient $\left(\sigma^{\circ}\right)$ series consists of all ASCAT observations at a single grid point, normalized to a reference angle of $40^{\circ}$. The backscattering coefficient from the land surface is influenced by a combination of static and dynamic factors. Static components include soil composition, surface roughness and land cover type which are assumed to be temporally stable at the scatterometer measurement scale (25$50 \mathrm{~km}$ ). Dynamic variations are due to the combined influence of vegetation and soil moisture on backscatter.

The backscattering coefficient $\sigma^{\circ}$ in decibels $[\mathrm{dB}]$ is assumed to be linearly related to surface soil moisture so that the soil moisture in the surface layer at 
(a) TU Wien Soil Moisture Retrieval Approach

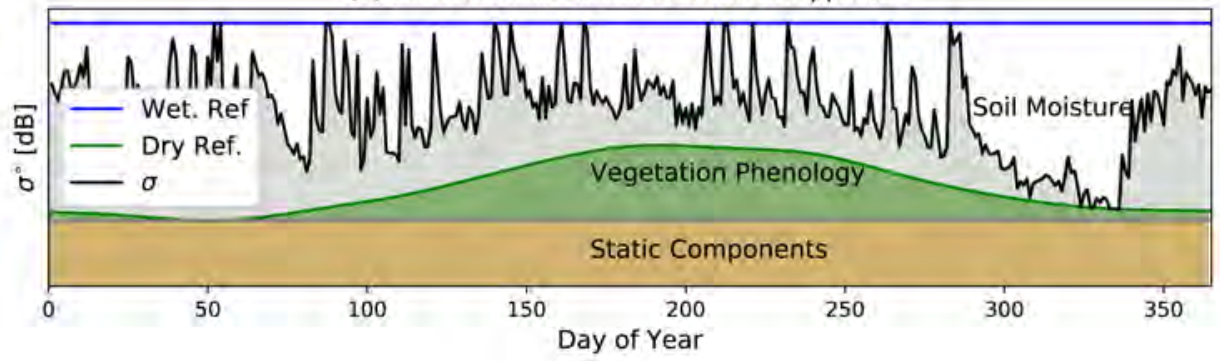

(b) Soil Moisture Change

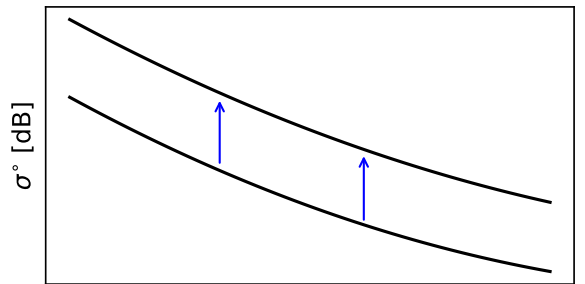

Incidence Angle $\theta$ [deg] (c) Vegetation Change

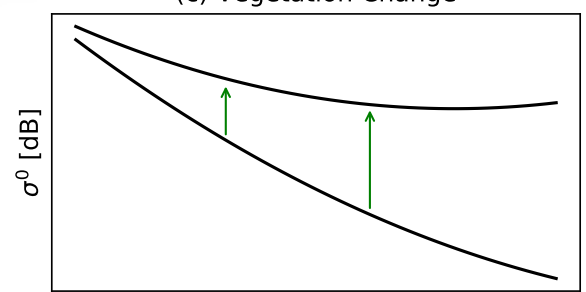

Incidence Angle $\theta$ [deg]

Figure 1: The top panel shows a time series of ASCAT data for a grid point in Nebraska to illustrate the concepts of dry reference, wet reference and observed normalized backscatter in the TU Wien Soil Moisture Retrieval (TUW SMR). The lower panel illustrates the impact of increasing soil moisture (b) and vegetation (c) on the incidence angle dependence of backscatter. 
some time $t$ is given by:

$$
\Theta_{s}(t)=\frac{\sigma^{\circ}\left(\theta_{r}, t\right)-\sigma_{d}^{\circ}\left(\theta_{r}, t\right)}{\sigma_{w}^{\circ}\left(\theta_{r}, t\right)-\sigma_{d}^{\circ}\left(\theta_{r}, t\right)}
$$

where $\sigma_{w}^{\circ}, \sigma_{d}^{\circ}$, and $\sigma^{\circ}$ are the wet and dry references, and backscattering coefficients (in $\mathrm{dB}$ ) at the reference incidence angle $\theta_{r}$ and time $t$. Seasonal variations in vegetation density determine the so-called "Dry Reference" backscattering coefficient. For a given date, this represents the lower limit of the range within which the backscattering coefficient varies due to soil moisture. The upper limit ("Wet Reference") is time-independent and reflects the highest value of backscattering coefficient observed at that grid point.

The relationship between backscattering coefficient and incidence angle is at the core of this TUW SMR approach. It is used to normalize the ASCAT backscatter measurements to the reference angle $\theta_{r}$. Wagner et al. [21] used ERS data to demonstrate that the slope $\left(\sigma^{\prime}\right)$ depends linearly on incidence angle $(\theta)$ :

$$
\sigma^{\prime}(\theta)=\sigma^{\prime}\left(\theta_{r}\right)+\sigma^{\prime \prime}\left(\theta_{r}\right) \cdot\left(\theta-\theta_{r}\right) \quad[d B / d e g]
$$

where $\theta_{r}$ is a reference incidence angle, set to $40^{\circ}$ in the TUW SMR approach. Hence, the dependence of backscattering coefficient on incidence angle can be described as a second order polynomial:

$$
\sigma^{\circ}(\theta)=\sigma^{\circ}\left(\theta_{r}\right)+\sigma^{\prime}\left(\theta_{r}\right) \cdot\left(\theta-\theta_{r}\right)+\frac{1}{2} \sigma^{\prime \prime}\left(\theta_{r}\right) \cdot\left(\theta-\theta_{r}\right)^{2} \quad[d B]
$$

Once the slope $\left(\sigma^{\prime}\left(\theta_{r}\right)\right)$ and curvature $\left(\sigma^{\prime \prime}\left(\theta_{r}\right)\right)$ are known, the scatterometer measurements at any incidence angle can be extrapolated to the reference angle of $\theta_{r}$ as follows:

$$
\sigma^{\circ}\left(\theta_{r}\right)=\sigma^{\circ}(\theta)-\sigma^{\prime}\left(\theta_{r}\right) \cdot\left(\theta-\theta_{r}\right)-\frac{1}{2} \sigma^{\prime \prime}\left(\theta_{r}\right) \cdot\left(\theta-\theta_{r}\right)^{2}
$$

This expression can also be re-arranged to extrapolate the backscatter at any incidence angle if the slope, curvature and $\sigma^{\circ}\left(\theta_{r}\right)$ are known.

The incidence angle behaviour of $\sigma^{\circ}$ depends on whether total backscatter is dominated by volume scattering from the vegetation or surface scattering from 
the soil. Over bare soils, $\sigma^{\circ}$ is expected to decrease sharply with increasing incidence angle due to the dominance of surface scattering. Figure 1(b) shows the $\sigma^{\circ}-\theta$ relationship on Days 334 (dry) and 353 (wet) to illustrate that an increase in soil moisture results in an increase in $\sigma^{\circ}$ for all incidence angles, i.e. a vertical offset in the $\sigma^{\circ}-\theta$ curve. Zribi et al [28] showed that soil roughness also influences slope and curvature. However soil roughness is assumed to be temporally stable at the scatterometer measurement scale $(25-50 \mathrm{~km})$. Over dense vegetation $\sigma^{\circ}$ becomes less sensitive to $\theta$ at steeper incidence angles. Figure $1(\mathrm{c})$ shows the difference between the $\sigma^{\circ}-\theta$ relationship on Day 334 (minimum vegetation) to that on 200 (maximum vegetation). An increase in vegetation cover is associated with a rotation, i.e. a change in slope and curvature, of this curve. In this way, variations in the slope and curvature are used in the TUW SMR to account for the influence of vegetation.

The slope and curvature coefficients of the Taylor polynomial are estimated from the backscatter triplets (fore, mid and aft beam) provided by Metop ASCAT. ASCAT is a fixed fan-beam scatterometer, with two sets of three sidewayslooking antennas each illuminating a $550 \mathrm{~km}$ wide swath on either side of the satellite track. The three antennas on each side are oriented at $45^{\circ}$ (fore), $90^{\circ}$ (mid) and $135^{\circ}$ (aft) to the satellite track. The incidence angle range of the fore and aft antennas is $34-65^{\circ}$, while the mid antenna covers $25-55^{\circ}$. This viewing geometry means that each location on the surface is observed with three slightly asynchronous, independent backscatter measurements ("backscatter triplets") with three independent viewing directions. The simultaneous backscatter observations of the three beams allow us to compute an instantaneous backscatter slope, also called the "local slope":

$$
\sigma^{\prime}\left(\frac{\theta_{m i d}-\theta_{a / f}}{2}\right)=\frac{\sigma_{m i d}^{\circ}\left(\theta_{m i d}\right)-\sigma_{a / f}^{\circ}\left(\theta_{a / f}\right)}{\theta_{m i d}-\theta_{a / f}} \quad[d B / d e g]
$$

where 'mid' indicates the midbeam antenna and the subscript 'a/f' indicates the aft beam or fore beam antenna.

A large number of local slope values must be combined to account for the substantial noise in individual values [29] and to ensure that the slope is sam- 
pled across a wide range of incidence angles. Hahn et al. 30. provide a detailed review of the different approaches that have been used to estimate the slope and curvature for various generations of soil moisture products from the ERS and ASCAT observations. The current suite of operational ASCAT-derived soil moisture products use several years of local slope data to produce a seasonal climatology of slope and curvature coefficients [22, 31]. This approach was essential for ERS-1/2 scatterometer data to ensure robust parameter estimates. However, the second set of three fan-beam antennas on ASCAT increased the number of backscatter observations available for the determination of the local slope values. This increased data density makes it possible to determine the slope and curvature dynamically, and hence to account for interannual variations.

Recently, Melzer [19] proposed a Kernal Smoother (KS) approach to determine the slope and curvature dynamically. An Epanechnikov kernel with width $\lambda=21$ is used to weight the local slope estimates by their temporal distance from a given day. Hence, the estimate of slope and curvature for a given day is based on all local slope values within a 42-day window, with those closer in time assigned higher weights. This kernel width was found to provide an acceptable balance between bias and variance in the estimate. Hahn et al. [30] performed a cross-comparison of the dynamic slope and curvature values estimated separately from Metop-A and Metop-B. The consistency of the estimated parameters from the two satellites is an indicator of the robustness of the estimate. Hövmoller diagrams, and time series plots at a limited number of locations demonstrated that the slope and curvature series exhibit both seasonal and interannual variations. The current study examines the temporal and spatial features of the slope and curvature variations more closely to evaluate their value as a source of information on vegetation phenology and water dynamics. 


\section{Data and Methods}

\subsection{Study Area}

The study domain is mapped in Figure 2 and extends from $28.6 \mathrm{~N}$ to $55 \mathrm{~N}$, and $90 \mathrm{~W}$ to $115 \mathrm{~W}$. The ASCAT data are organized on a fixed Earth grid described by Naeimi et al. [18. Grid points considered as Grasslands (class 130) were identified using the ESA CCI Land Cover product. The original sampling resolution of this product is $300 \mathrm{~m}$, therefore the land cover class assigned to each grid point represents the mode within a $25 \mathrm{~km}$ x $25 \mathrm{~km}$ window 32 . The study domain includes 14,585 grid points and encompasses the contiguous North American Temperate Grasslands extending from Alberta and Saskatchewan to Texas [33. The Köppen Geiger Climate Classes (KGCC) of the grid points are mapped in Figure 2. These are based on temperature and precipitation observations for the period 1951-2000 34]. An overview of the KGCCs, including the climate type, precipitation class, temperature sub-class and prevalence in the study domain is provided in Table 1. The four dominant Köppen Geiger Classes are BSk, Cfa, Dfb and Dfa, which together cover $96.6 \%$ of the domain.

The ecoregions in the study domain are mapped in Figure 3 based on the WWF Terrestrial Ecosystems of the World [33. The arid, cold steppe (BSk) class is dominated by short grasslands. The temperate class ( $\mathrm{Cfa}$ ) is more diverse and includes short grassland in the Texas panhandle, the Texas Blackland Prairies and stretches through mixed grasslands, and the forest-grasslands transition to the forests of Eastern Texas and Oklahoma. The Dfa class extends from the mixed grasslands of Nebraska and Kansas to tall grasslands and the grasslands/forest transition to the east. Further north, the Dfb class transitions from tall grasslands at the $100 \mathrm{~W}$ meridian to mixed and short grasslands further west. The diversity of KGCC and ecoregions within the domain highlights the heterogeneity within the "grasslands" land cover class. Furthermore, while "grasslands" may be the mode (most commonly occuring class) within a $25 \mathrm{~km}$ x $25 \mathrm{~km}$ window, examination of the 300 m product shows that the grassland ecosystems are increasingly being encroached by agricultural land use. This is 


\begin{tabular}{|c|c|c|c|c|}
\hline KGCC & $\begin{array}{c}\text { Climate } \\
\text { Type }\end{array}$ & $\begin{array}{c}\text { Class } \\
\text { (Precipitation) }\end{array}$ & $\begin{array}{c}\text { Sub-class } \\
\text { (Temperature) }\end{array}$ & $\begin{array}{c}\% \text { of grid points } \\
\text { in study area }\end{array}$ \\
\hline BSk & Arid & Steppe & Cold & 34.2 \\
Cfa & Temperate & Without dry season & Hot Summer & 24.4 \\
Dfb & Cold & Without dry season & Warm Summer & 20.0 \\
Dfa & Cold & Without dry season & Hot Summer & 18.0 \\
Dfc & Cold & Without dry season & Cold Summer & 1.1 \\
BWk & Arid & Desert & Cold & $<1$ \\
Dwb & Cold & Dry Winter & Warm Summer & $<1$ \\
Dsb & Cold & Dry Summer & Warm Summer & $<1$ \\
BSh & Arid & Steppe & Hot & $<1$ \\
Dwa & Cold & Dry Winter & Hot Summer & $<1$ \\
Dsa & Cold & Dry Summer & Hot Summer & $<1$ \\
Cfb & Temperate & Without dry season & Warm Summer & $<1$ \\
\hline
\end{tabular}

Table 1: Dominant Köppen Geiger Climate Classes (KGCC) [34], and their prevalence in the study area.

particularly true of the tall and mixed grassland areas 35 .

\subsection{ASCAT data}

Ten years of Metop-A ASCAT SZR Level 1b Fundamental Climate Data Record backscatter data, using the $12.5 \mathrm{~km}$ swath grid sampling, were obtained from the EUMETSAT Data Centre. Three standard pre-processing steps were performed: (1) the backscatter observations were resampled to a fixed Earth grid using a Hamming window function and the procedure described by Naeimi et al. [18; (2) An intra- and interbeam calibration was performed using natural extended calibration targets over land [36; and (3) the empirical approach of Bartalis et al. 37] was used to account for azimuthal effects.

Metop-A and Metop-B fly in a sun-synchronous orbit with a 29-day repeat cycle orbit and equatorial crossing times of 09:30 AM and PM (Local Solar Time) in descending and ascending nodes [38]. Further steps were performed 


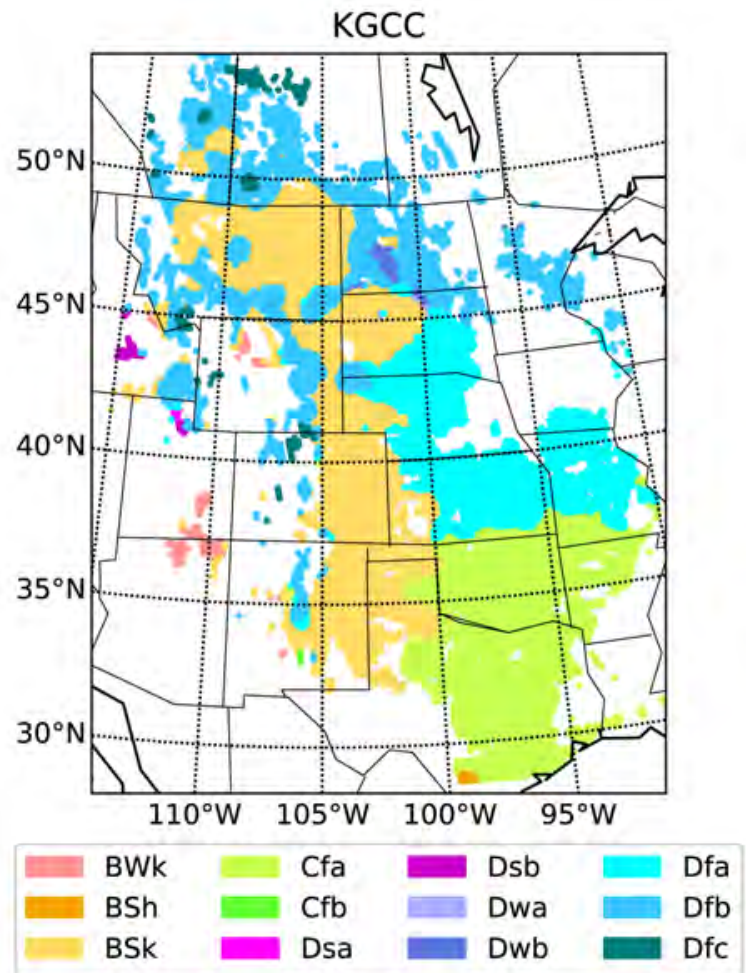

Figure 2: Grid points in the study domain, colored by their Köppen Geiger Climate Class (KGCC) 34] 


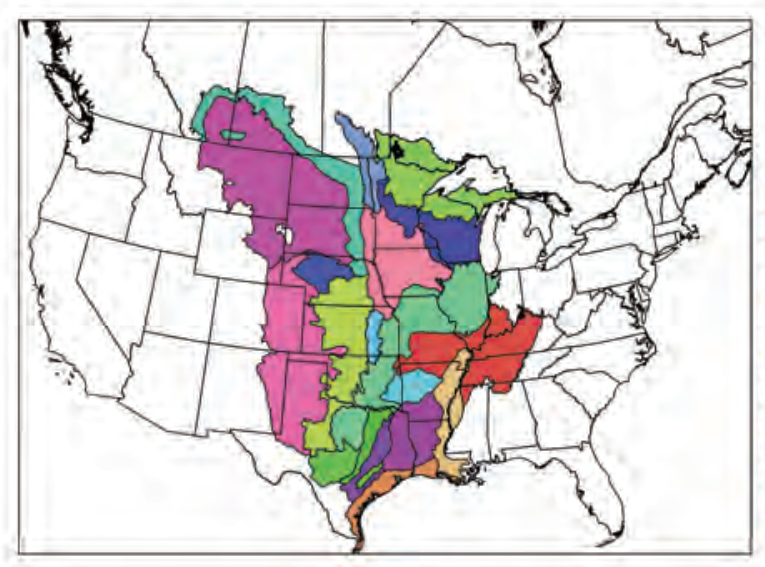

Legend

$\square$ Province boundaries Canada

$\checkmark$ State boundaries USA

Ecoregion:

$\square$ Central and Southern mixed grasslands

$\square$ Central forest-grasslands transition

Central tall grasslands

$\square$ Central U.S. hardwood forests

East Central Texas forests

Edwards Plateau savanna

$\square$ Flint Hills tall grasslands

$\square$ Mississippi lowland forests

Nebraska Sand Hills mixed grasslands

Northern mixed grasslands

Northern short grasslands

Northern tall grasslands

Ozark Mountain forests

Piney Woods forests

Texas blackland prairies

Upper Midwest forest-savanna transition

Western Great Lakes forests

Western Gulf coastal grasslands

Western short grasslands

Figure 3: Ecoregions in the study domain 33.

on (1) descending overpasses only, (2) ascending overpasses only or (3) the entire dataset consisting of both the descending and ascending overpasses. For each of these overpass combinations, the backscatter triplets were used to calculate the local slope using equation (5). The methodology proposed by Melzer [19] was used to estimate the slope and curvature from these local slopes, assuming a kernel width of 21 days. These slope and curvature values were combined with the corresponding (i.e. descending, ascending or all) normalized backscattering coefficient $\left(\sigma_{40}^{\circ}\right)$ to derive soil moisture using the TUW SMR.

For each grid point in the study domain, the 10-year time series of slope, curvature, normalized $\left(40^{\circ}\right)$ backscattering coefficient and derived soil moisture were extracted. For the slope and curvature, the seasonal climatology was determined by averaging the daily values across the 10 years. The revisit time dictates that observations from the descending and ascending overpasses are unlikely to occur on the same day, and that a limited number of values are available for a given day of the year. Therefore, the seasonal climatology of $\sigma_{40}^{\circ}$ and soil moisture were determined after first aggregating their data into 10 day 


\begin{tabular}{|c|c|c|c|c|c|}
\hline Abbreviation & $\begin{array}{l}\text { Northwest } \\
\text { Corner }\end{array}$ & $\begin{array}{l}\text { Southeast } \\
\text { Corner }\end{array}$ & KGCC & Ecoregion & $\begin{array}{l}\text { No. } \\
\text { grid } \\
\text { points }\end{array}$ \\
\hline N. Shortgrass & $\begin{array}{l}\left(48.87^{\circ} \mathrm{N},\right. \\
\left.107.63^{\circ} \mathrm{W}\right)\end{array}$ & $\begin{array}{l}\left(46.03^{\circ} \mathrm{N}\right. \\
\left.104.15^{\circ} \mathrm{W}\right)\end{array}$ & BSk & $\begin{array}{l}\text { Northern } \\
\text { Shortgrass } \\
\text { Prairie }\end{array}$ & 544 \\
\hline W. Shortgrass & $\begin{array}{l}\left(40.97^{\circ} \mathrm{N}\right. \\
\left.104.06^{\circ} \mathrm{W}\right)\end{array}$ & $\begin{array}{l}37.03^{\circ} \mathrm{N} \\
102.07^{\circ} \mathrm{W}\end{array}$ & BSk & $\begin{array}{l}\text { Western } \\
\text { Shortgrass } \\
\text { Prairie }\end{array}$ & 460 \\
\hline Mixed Grass & $\begin{array}{l}\left(36.96^{\circ} \mathrm{N}\right. \\
\left.99.59^{\circ} \mathrm{W}\right)\end{array}$ & $\begin{array}{l}\left(33.98^{\circ} \mathrm{N}\right. \\
\left.98.21^{\circ} \mathrm{W}\right)\end{array}$ & $\mathrm{Cfa}$ & $\begin{array}{l}\text { Central- } \\
\text { Southern } \\
\text { U.S. Mixed } \\
\text { Grasslands }\end{array}$ & 243 \\
\hline Transition & $\begin{array}{l}\left(40.54^{\circ} \mathrm{N}\right. \\
\left.95.73^{\circ} \mathrm{W}\right)\end{array}$ & $\begin{array}{l}\left(38.57^{\circ} \mathrm{N}\right. \\
\left.93.42^{\circ} \mathrm{W}\right)\end{array}$ & Dfa & $\begin{array}{l}\text { Central } \\
\text { Forest- } \\
\text { Grasslands } \\
\text { Transition }\end{array}$ & 207 \\
\hline
\end{tabular}

Table 2: Description of the four Regions of Interest used to examine the seasonal climatology of the ASCAT data.

intervals (dekads).

Four Regions of Interest (ROIs) are used to investigate the seasonal climatology and interannual variability of the nominal parameters and their diurnal differences as a function of landscape. The KGCC, ecoregion and bounding coordinates of each of the ROIs is given in Table 2 Spatial averaging is performed after the seasonal climatologies and anomalies have been determined for the individual grid points. 


\section{Results and Discussion}

\subsection{Seasonal Climatology}

Figure 4 shows that the time series of slope and curvature are smoother than that of $\sigma_{40}^{\circ}$ (c) itself. This is partly due to each daily estimate of slope and curvature being based on local slope estimates within a 42-day window. Also, the physical and biological processes driving the slope and curvature act on time scales longer than changes in soil surface wetness. Slope values (Figure 4 (a-d)) increase from west to east due to the increased vegetation density from the short grasslands, through the mixed grasslands and into the forest/grassland transition ROIs. The seasonal dynamics of slope in the four ROIs are markedly different. The shortest peak is observed in the northern shortgrass while double peaks are observed in both the western shortgrass and mixed grasslands ROIs. The higher slope values of the mixed grasslands suggest some vegetation cover persists year-round. Spring brings an increase which is sustained until early September. The highest vegetation density is observed in the transition ROI, also the wettest part of the domain. Mixed forest and agricultural production in this ROI explain the comparatively high slope values, the increase in vegetation density from April to mid-July and the relatively rapid decrease in the autumn.

The seasonal dynamics observed in Figure 4 (e-h) suggest that curvature is related to vegetation, though the curvature is clearly not directly related to slope. Across most land covers, the curvature is close to zero and relatively constant. Hahn et al. 30 showed that grasslands typically have a positive curvature, i.e. the $\sigma_{40}^{\circ}-\theta$ relationship flattens out or curves upwards at high incidence angles. Positive curvature has been simulated and observed in grasses, wheat and barley and has been linked to their vertical structure [39, 40, 41]. Stiles et al. 42 discussed this phenomenon using modeled and measured data for a wheat canopy prior to the emergence of the grain head. At lower incidence angles $\left(<30^{\circ}\right)$, scattering is dominated by mechanisms involving a "groundbounce". As $\theta$ increases, the electric field of the vertically polarized incidence wave becomes increasingly coupled with the vertical structure of the plant. The 
impact is two-fold. First, the increasing $\theta$ results in increased attenuation of the ground-bounce terms. Second, direct scattering from the upper portion of the vertical stalk and the grain (inside) increases with $\theta$. In the wheat canopy, Stiles et al. observed that the combination of these two effects is a backscatter minimum at around 40-50 degrees. The positive curvature values and their seasonal variations observed in Figure $4(\mathrm{e}-\mathrm{g})$, indicate that a similar mechanism may be evident in the North American grasslands.

In all of the grasslands ROIs, the curvature increases during the spring. This could be explained by the development of the predominantly vertical structure. In the Northern short grasslands, the large positive curvature values are sustained until the vegetation density (slope) decreases in the autumn. In the Western Shortgrass and Mixed grasslands (ROI), both the slope and curvature exhibit a dip during the maximum biomass period. This suggests that the strength of the influence of the vertical structure varies during the summer. This could be related to either a change in the water content of the vertical stalks, or to the emergence of flowers, fruit or other plant types with more randomlyoriented scatterers. In the mixed grasslands ROI, the curvature decreases to the winter value in the late summer, i.e. the influence of the vertical structure is greatly diminished. The seasonal cycle in the transition ROI differs considerably from the grasslands. It decreases to almost zero during the maximum biomass period and is occasionally negative due to the presence of forest and agriculture in this ecosystem.

Seasonal variations in backscatter and soil moisture are limited in all four ROIs. The increasing (soil and vegetation) moisture from west to east is apparent in $\sigma_{40}^{\circ} \mathrm{Fig} 4$ (i to 1$)$. Seasonal variations are about $2 \mathrm{~dB}$ in all ROIs. The largest seasonal variation in soil moisture is observed in the Transition ROI while the variation is limited to $25 \%$ in the grasslands. The interannual variations in backscatter and soil moisture are comparable in magnitude to the seasonal variations in all but the Transition ROI. The standard deviation is typically about $17 \%$ of the seasonal range of the vegetation parameters. Given the strength of the seasonal cycle, this suggests that interannual variability in 

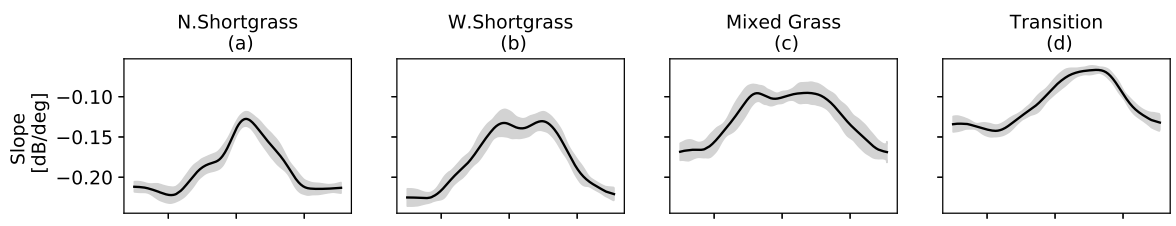

(e)
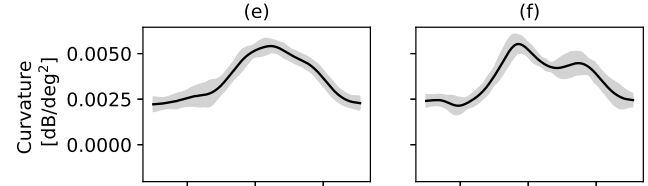

(g)

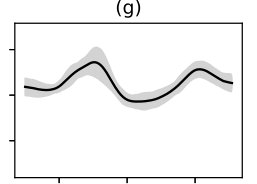

(h)

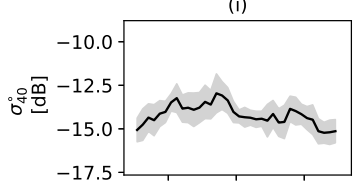

(j)

(k)
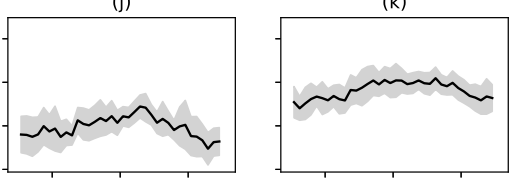

(o)
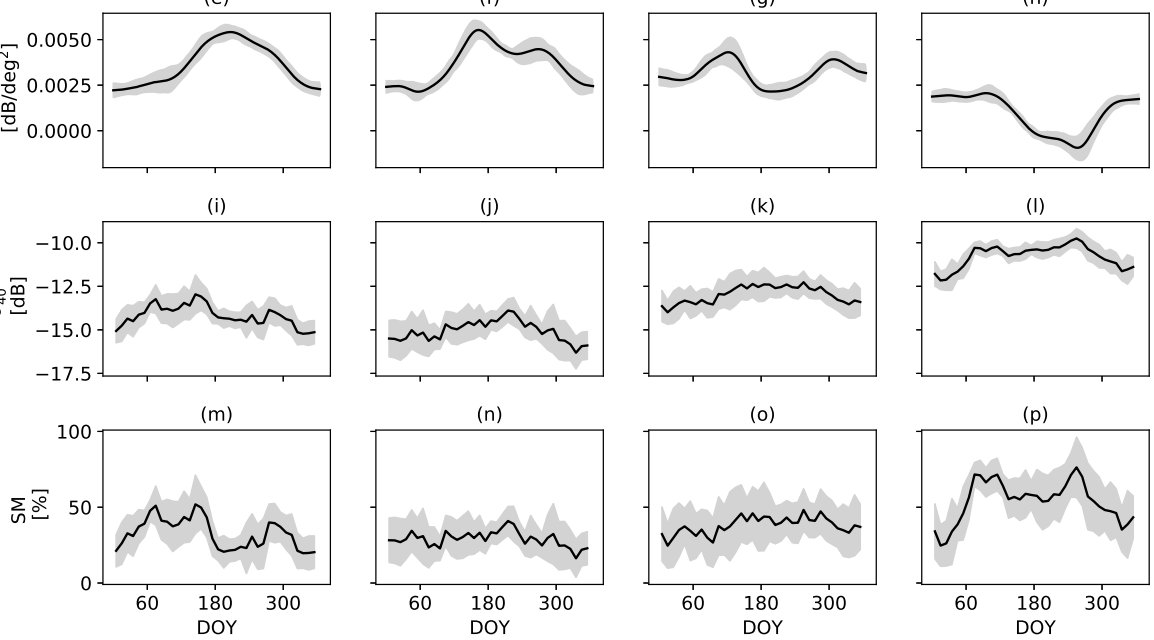

(I)

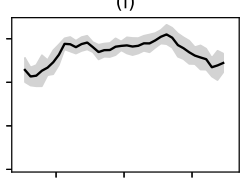

(p)

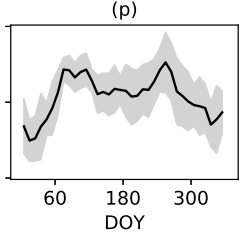

Figure 4: Mean annual cycle of slope (a)-(d), curvature (e)-(h), $\sigma_{40}^{\circ}(\mathrm{i})-(\mathrm{l})$ and soil moisture $(\mathrm{m})-(\mathrm{p})$, averaged across each of the four Regions of Interest. Results are presented from the combined dataset that uses data from both the descending and ascending overpasses. The black line corresponds to the mean seasonal cycle, and the grey area indicates \pm one standard deviation as a measure of the interannual variability.

soil moisture has a significant effect on the vegetation parameters.

A convenient way to synthesize the influence of the changes observed in the slope, curvature and $\sigma_{40}^{\circ}$ is to consider their combined impact on the $\sigma^{\circ}-\theta$ relationship which is shown in Figure 5 to vary considerably during the year. The steepest curves and the largest variations during the year are observed in the shortgrass areas (Fig.5(a)) and Fig. (5(b)). This indicates that the influence of vegetation on soil moisture sensitivity is highly dynamic in these areas. The presence of some vegetation throughout the year results in less negative slope values in the mixed grass (Fig. 5(c)) and transition area (Fig. 5(d)). 

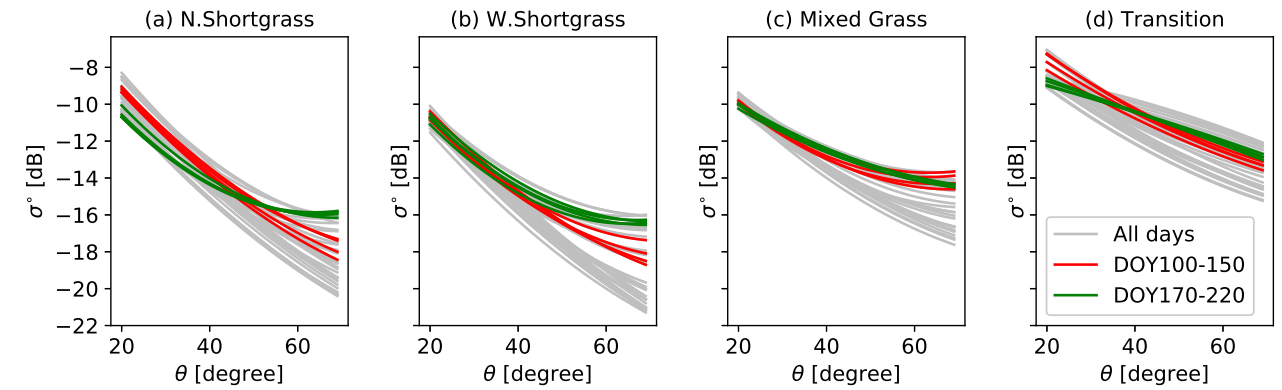

Figure 5: Backscattering coefficient as a function of incidence angle for each of the four ROIs, calculated using all data (i.e. combined descending and ascending overpasses). Each grey line corresponds to the climatology of a single 10-day period (dekad) during the year, averaged across the KG climate class. The red and green lines indicate dekads in the early growing season (DOY 100-150) and maximum biomass period (DOY 170-220).

In each of the cover types, the winter months are characterized by the lowest backscatter and steepest slopes of the year. The start of the growing season (around DOY 100-150) corresponds to a period of increased soil moisture in the Northern Shortgrass (a) and the Transition area (d). The red curves, corresponding to this period, are vertically offset but parallel to the winter values. In the Western Shortgrass (b) and Mixed Grass (d), the soil moisture is more constant throughout the year, so this vertical offset is not evident. In the shortgrass ROIs, the combined changes in slope and curvature during the biomass accumulation period result in a clear rotation in the $\sigma^{\circ}-\theta$ curve. During the biomass peak, the sensitivity to incidence angle at higher incidence angles is reduced. In the mixed grass, the curvature is at a minimum during the peak, so the $\sigma^{\circ}-\theta$ curve is almost linear. In the transition area, the $\sigma^{\circ}-\theta$ curve even becomes convex during the biomass peak.

As an indicator of interannual variability, Fig 6 (a)-(c) shows drought severity during the maximum biomass period in 2007, 2011 and 2012. The maps are weekly assessments of drought intensity in the previous week based on data through to the preceding Tuesday morning. The study domain was almost drought-free during the maximum biomass period in 2007, with D2 conditions 

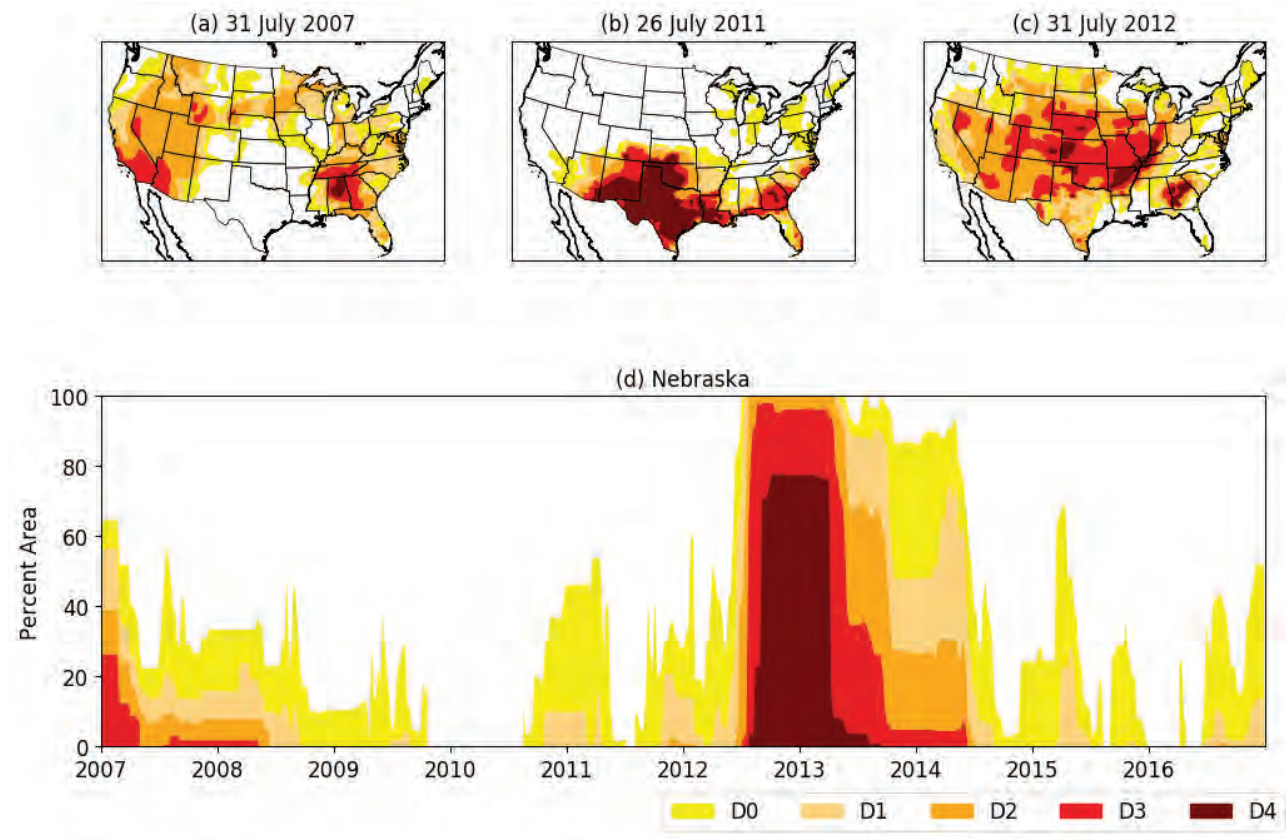

Figure 6: The top panel shows maps (a)-(c) from the United States Drought Monitor showing the drought severity at the end of July for 2007, 2011 and 2012. The lower panel (d) shows the time series of drought severity for the state of Nebraska, which includes the Nebraska Sand Hills. Map and time series courtesy of NDMC-UNL.

limited to western Nebraska, and South Dakota. A severe drought occurred in 2011 but its extent was limited to the southern part of the domain, namely Texas and much of Oklahoma. In 2012 a less severe, though more widespread, drought was observed with Oklahoma and Nebraska being particularly severely affected.

Figure 7 shows the influence of inter-annual variability on the $\sigma^{\circ}-\theta$ relationship in each of the ROIs. Each curve was calculated using the average slope, curvature and $\sigma_{40}^{\circ}$ value for the the maximum biomass period DOY 170-220) in a given year. The extensive drought in 2012 yielded the lowest $\sigma^{\circ}-\theta$ curve in all but the Mixed Grass class. In N. Shortgrass, the interannual variability and the 2012 drought are primarily apparent as an offset of up to $1.5 \mathrm{~dB}$, suggesting that the soil moisture anomaly did not have a serious effect on the vegetation. 

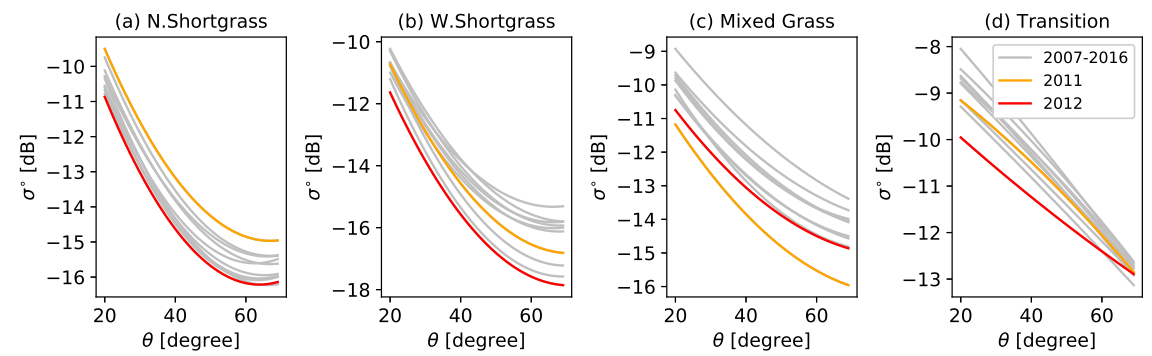

Figure 7: Backscattering coefficient as a function of incidence angle, during the maximum biomass period (DOY 170-220) for each of the four ROIs. Each grey line corresponds to the average value per year from 2007 to 2016. The "drought years" of 2011 and 2012 are highlighted in orange and red respectively.

In the W. Shortgrass, a difference in slope is apparent, suggesting that the soil moisture anomaly impacted vegetation. In general, interannual variability in the Mixed Grass ROI appears to be a vertical offset due to soil moisture availability. However, the extreme drought in 2011 in this ROI also produced a change in slope and curvature. The effect of drought is most apparent at lower incidence angles in the Transition ROI. This suggests that drought conditions primarily affect the soil moisture. Interannual variability at $\theta=60^{\circ}$ is less than $1 \mathrm{~dB}$ suggesting limited interannual variability in scattering from vegetation.

Figure 8 shows the seasonal cycle of the diurnal difference of the slope, curvature, $\sigma_{40}^{\circ}$ and soil moisture for each of the four ROIs. During the summer, the slope is steeper during the descending pass (9:30 AM) than during the ascending pass (9:30 PM). The largest difference $(0.0105 \mathrm{~dB} / \mathrm{deg})$ is observed in the Northern Shortgrass ROI, at around day 200 ( 20 July). Note that this corresponds to more than $10 \%$ of the annual dynamic range, so the diurnal variations are substantial. Given the assumption that the slope represents "vegetation density", one might expect vegetation water content to be higher in the morning and to be reduced due to transpiration during the day. However, this apparent contradiction may be due to the overpass time. Plant water content has a predawn maximum. Transpiration rates, particularly in anisohydric species, are very high in the early morning. Until stomatal control limits ET, water losses 
due to transpiration may lead to a transient reduction in plant water content, and particularly leaf water content, before midday.

Diurnal differences in curvature are positive during the summer months, and they do not co-vary with those observed in the slope. Curvature differences of around $0.0005 \mathrm{~dB} / \mathrm{deg}^{2}$ (12\% of the annual dynamic range) are observed in all but the Mixed Grassland ROI. Lower curvature values in the ascending (evening) pass suggest that the ground-bounce contribution to total backscatter is more important in the evening. In addition to plant water variations, slope and curvature may be affected by geometry effects, e.g. heliotropism or leaf rolling to control stomatal conductance. The timing and sign of diurnal differences in backscatter and soil moisture are similar. Both are higher in the morning throughout the growing season in the Northern shortgrass ROI. In the other cover types, both are lower during the descending pass during the biomass peak.

Figure 9 shows how the $\sigma_{40}^{\circ}-\theta$ relationship differs between the descending and ascending passes during the biomass peak. There is no vertical offset between the curves, but there is some rotation in all ROIs. This rotation suggests that the diurnal differences are dominated by differences in the vegetation parameters. The largest difference is observed in the N. Shortgrass ROI. The difference at $40^{\circ}$, the reference angle for soil moisture retrieval in TUW SMR, is barely discernible. Figure 9 suggests that variations in vegetation water content and structure during the day result in changes to the relative importance of the ground-bounce and direct scattering from the vertical constituents of the canopy.

\subsection{Spatial Patterns}

Figure 10 shows the 10-year average of the vegetation parameters, $\sigma_{40}^{0}$ and soil moisture across the study domain during the start of the growing season. From Figure 10 (a), the shallowest slopes are observed in the southeast where the lack of dry season means that there is vegetation present even during the winter months. Conversely, the steepest slopes are observed in the north of the study domain, where bare and possibly frozen soil delays the start of the 


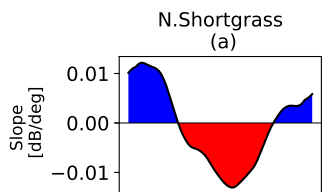

(e)

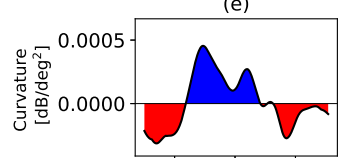

(i)

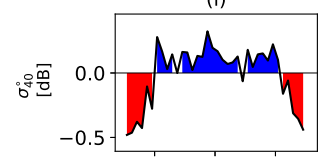

(m)

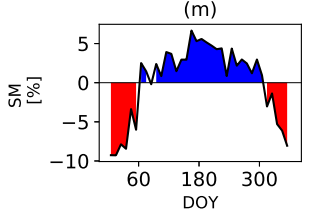

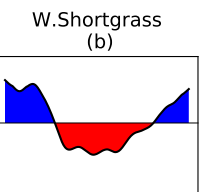

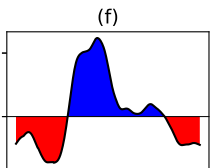

(j)

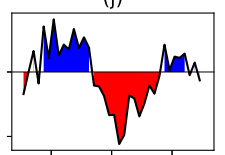

(n)

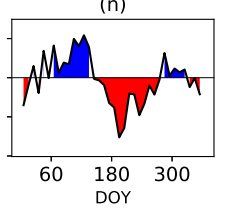

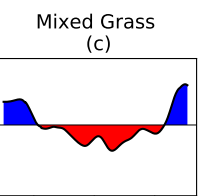

(g)

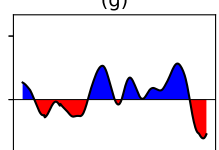

(k)

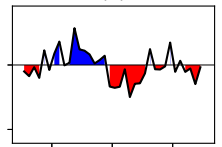

(o)

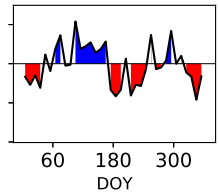

Transition

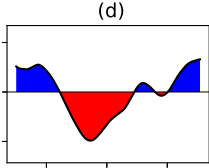

(h)

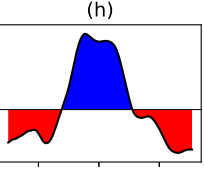

(I)

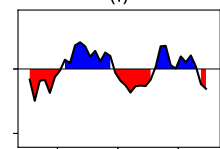

(p)

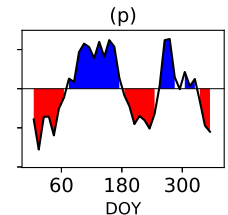

Figure 8: Annual cycle of the diurnal (descending - ascending) difference in slope (a)-(d), curvature (e)-(h), $\sigma_{40}^{\circ}(\mathrm{i})-(\mathrm{l})$, and soil moisture (m)-(p). Each column corresponds to values averaged across all grid points in each of the four Regions of Interest.

(a) N.Shortgrass

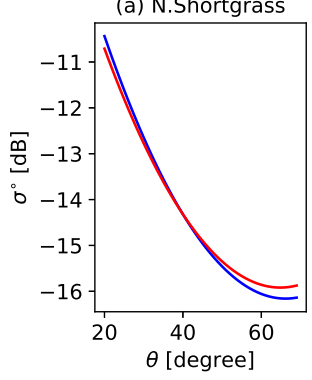

(b) W.Shortgrass

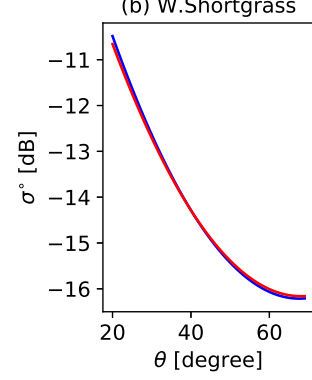

(c) Mixed Grass

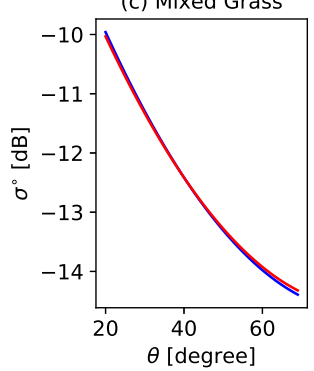

(d) Transition

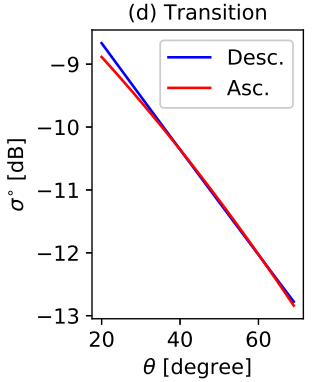

Figure 9: Backscattering coefficient as a function of incidence angle during the maximum biomass period (DOY 170-220) for each of the four dominant Köppen Geiger climate classes. The blue and red lines correspond to the curve estimated using data from the descending and ascending overpasses respectively. 
growing season. The curvature (Fig $10(\mathrm{~b}))$ is positive everywhere except in the southeast, probably due to the presence of forest. A clear east-west gradient is apparent in the $\sigma_{40}^{\circ}$ and soil moisture values. The wettest areas are found in eastern Oklahoma, eastern Kansas, Missouri and Arkansas where mixed and tall grasslands transition to forest. The $\sigma_{40}^{\circ}$ values are also highest in the southeast, due to the higher soil moisture and higher slope (vegetation). The driest areas are to the west of the $100 \mathrm{~W}$ meridian in the short grassland areas.

Figure 11 shows the diurnal difference in the same quantities. Both $\sigma_{40}^{\circ}$ (Fig. 11(c)) and soil moisture (Fig. 11(d)) are generally higher during the descending (morning) overpass than during the ascending pass (evening). This is consistent with backscatter being dominated by soil moisture contribution at this time of year, and soil moisture decreases due to evaporation during the day. The slope (Fig. 11(a)) is steeper and the curvature (Fig. 11(b)) is more positive during the descending pass. This suggests that the vegetation is less opaque during the descending pass. One possible explanation for this counter-intuitive result is the ASCAT acquisition time (10 a.m/10 p.m. local time). Observations from the descending overpass are acquired after the vegetation has been transpiring for several hours and before the stomata may adjust to limit transpiration. Observations from the ascending pass are acquired several hours after peak transpiration when the vegetation has had time to draw moisture from the root zone.

Figure 12 shows the mean vegetation parameters, $\sigma_{40}^{\circ}$ and soil moisture values during the biomass peak (DOY 170-220). Generally, vegetation is denser than in Figure 10. The slope is less negative, so the backscatter is more sensitive to vegetation and less sensitive to soil moisture than in the earlier part of the growing season. The curvature remains positive everywhere except in the south east of the domain.The backscatter values still exhibit an east-west gradient, with a minimum to the west of the $100 \mathrm{~W}$ meridian. Soil moisture is lower everywhere compared to Figure 10(d), particularly in the short grasslands.

The spatial pattern of the diurnal differences in $\sigma_{40}^{\circ}$ and soil moisture are very different to those observed at the start of the growing season, particularly 

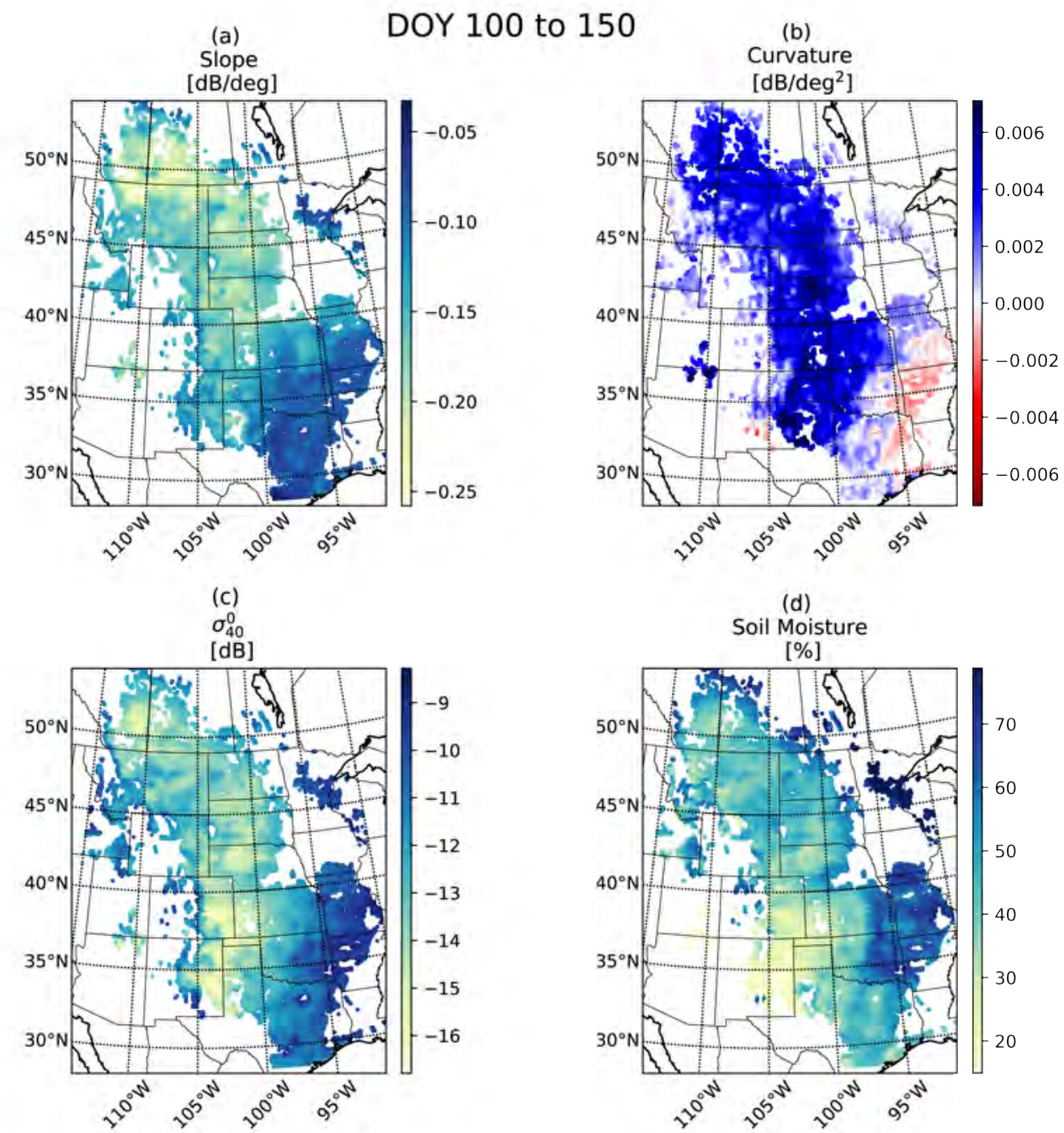

Figure 10: Climatological mean slope (a), curvature (b), $\sigma_{40}^{\circ}(\mathrm{c})$ and soil moisture (d) for each grid point during the period from DOY 100-150, calculated using all (descending and ascending) data. 


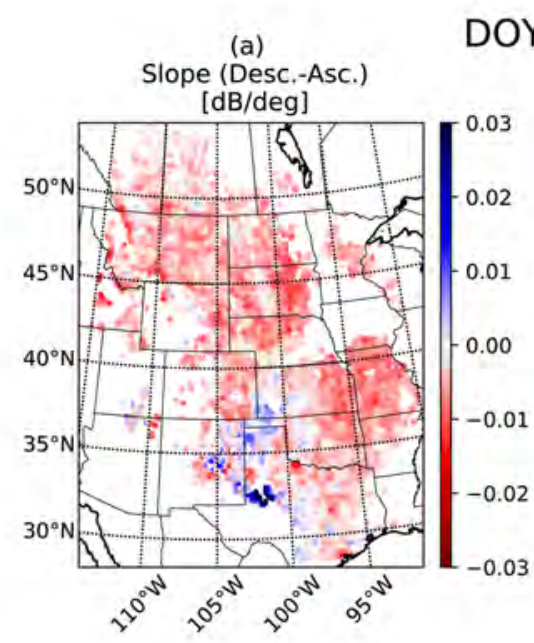

(b)

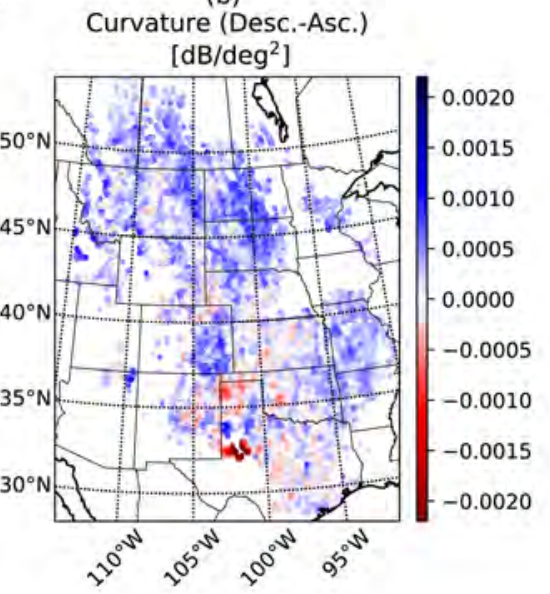

(c)

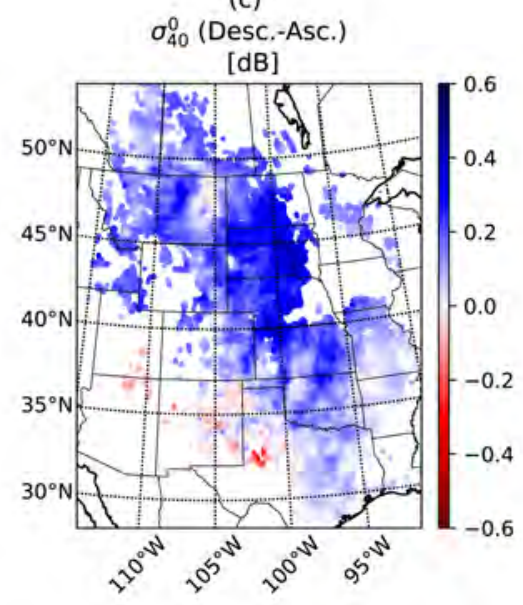

(d)

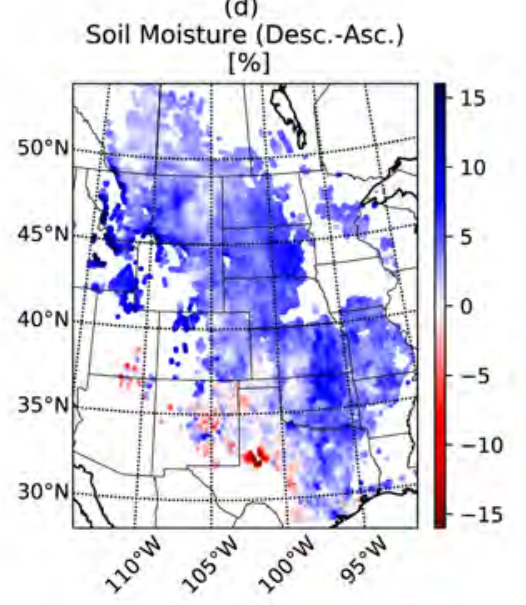

Figure 11: The difference between the values of slope (a), curvature(b), $\sigma_{40}^{\circ}(\mathrm{c})$ and soil moisture (d) calculated using the descending and ascending overpass data alone for the period DOY $100-150$. 

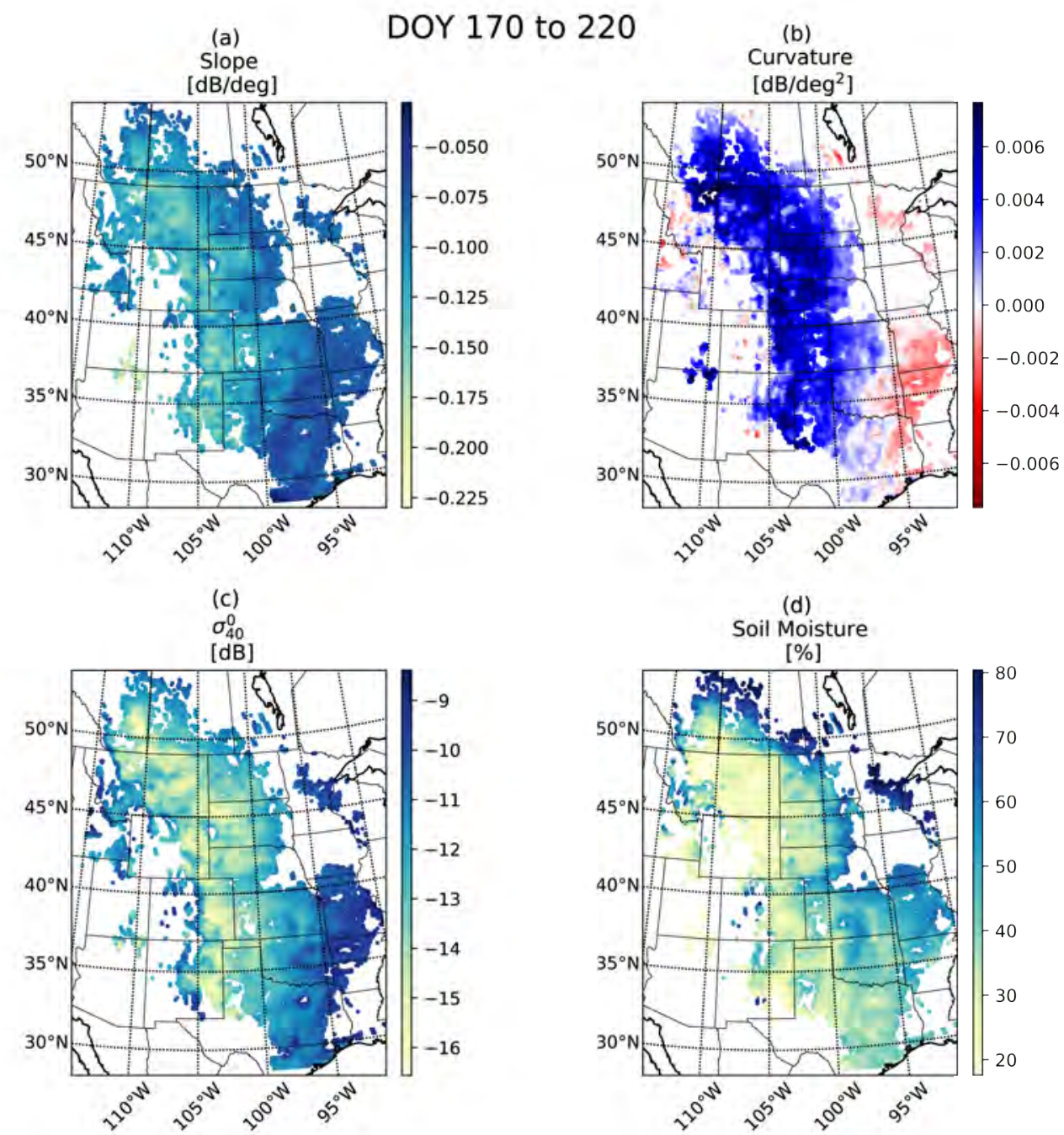

Figure 12: Climatological mean slope (a), curvature (b), $\sigma_{40}^{\circ}(\mathrm{c})$ and soil moisture (d) for each grid point during the period from DOY 170-220, calculated using all (descending and ascending) data. 
west of the $100 \mathrm{~W}$ meridian (Fig 13 ). In the Northern Short grasslands, $\sigma_{40}^{\circ}$ and soil moisture from the descending overpass (10 am) are still higher those from the ascending pass $(10 \mathrm{pm})$. However, in the Western Shortgrass Prairie, the opposite is true. It is particularly striking that the daily dynamics of the soil moisture are distinct from those of the vegetation, and that there is such strong difference between the Northern and Western Shortgrass areas. The magnitude of the diurnal difference in slope (Fig. $13(\mathrm{e})$ ) is considerably higher than earlier in the season, and the effect is particularly strong in the shortgrass prairies west of the $100 \mathrm{~W}$ meridian. The strongest negative backscatter and soil moisture differences are observed in areas with the highest abundance of $\mathrm{C}_{4}$ shortgrass (New Mexico and Colorado) and $\mathrm{C}_{3}$ shortgrass (east Wyoming) 43 .

Figure 14 shows that contiguous anomalies in slope and curvature are observed in areas affected by drought. Negative slope anomalies are observed in western Nebraska and South Dakota in 2007. They are also observed in the short grassland areas centered around the Texas Panhandle in 2011. In 2012, the negative slope anomalies are generally found further north in Nebraska, South Dakota and Colorado where the D3 conditions are indicated by the US Drought Monitor. Positive curvature anomalies are observed in the droughtaffected areas in the south in 2011, and further north in 2012. Particularly strong positive anomalies in curvature are observed in the Nebraska Sand Hills (41 N to $42.5 \mathrm{~N}, 101 \mathrm{~W}$ to $102 \mathrm{~W}$ ) in 2007 and 2012. These coincide with negative slope anomalies in the same area. The Dfa area in the north shows a positive anomaly during the dry conditions in 2007 and 2012 and a negative anomaly during 2011.

Similar spatial patterns are observed in the $\sigma_{40}^{\circ}$ and soil moisture anomalies (Fig. 15). The large positive anomalies in the south of the domain in 2007 are due to extreme rainfall events in mid-June when a frontal system resulted in heavy rains and extensive flooding in Texas and Oklahoma. The severe drought event of 2011 resulted in a $2 \mathrm{~dB}$ negative anomaly in $\sigma_{40}^{\circ}$ and anomalies of around $40 \%$ in soil moisture. In 2012, a negative soil moisture anomaly is observed across the study domain, with the most severe values in the eastern 


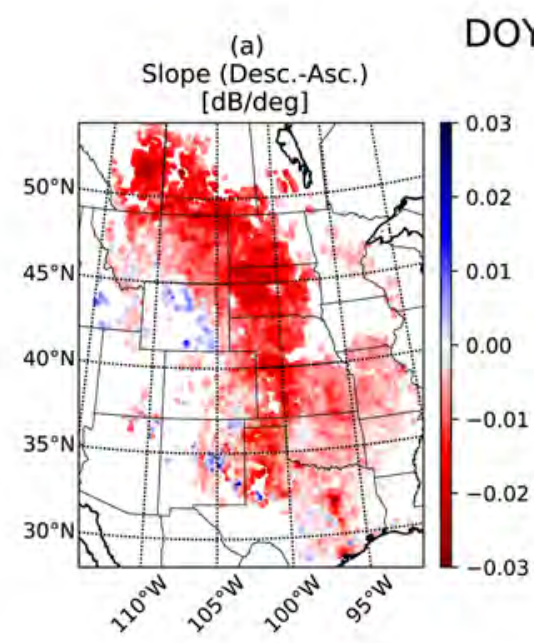

170 to 220

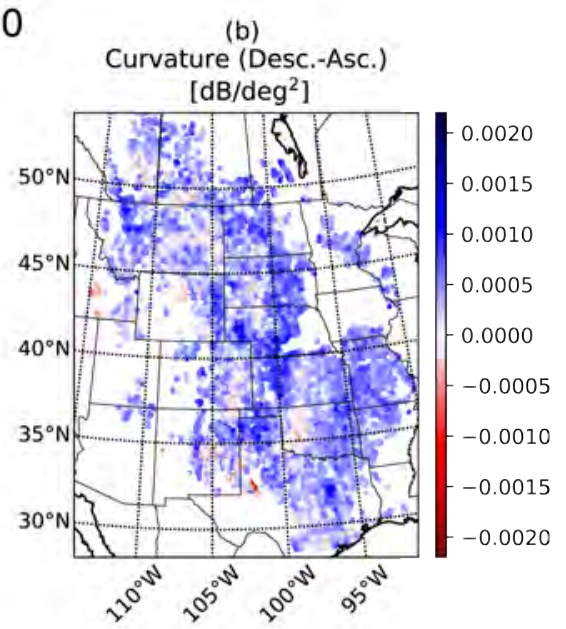

(c)

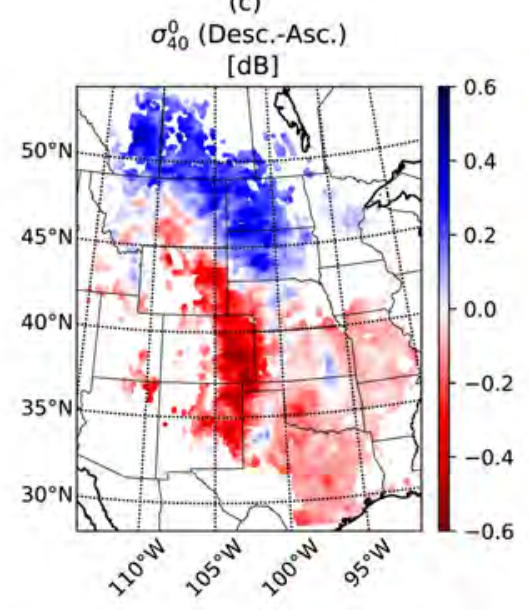

(d)

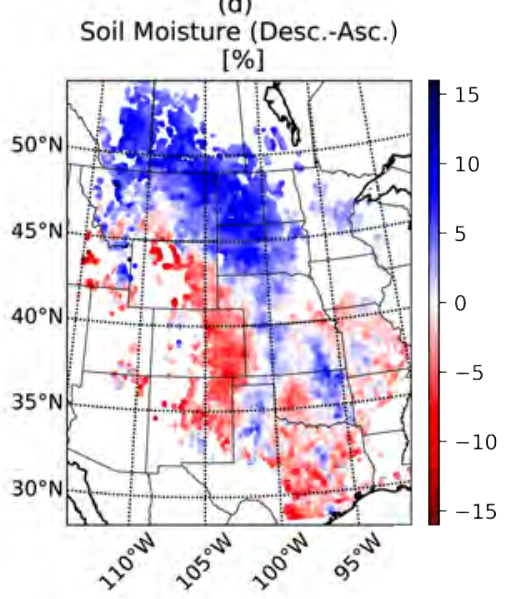

Figure 13: The difference between the values of slope (a), curvature(b), $\sigma_{40}^{\circ}$ (c) and soil moisture (d) calculated using the descending and ascending overpass data alone for the period DOY 100-150. 
part of the study area. The largest backscatter anomalies are observed between the $100 \mathrm{~W}$ and $105 \mathrm{~W}$ meridians, in the mixed grassland areas. Together with the observed anomalies in slope, this suggests that backscatter contributions from the vegetation were also lower than normal.

The occurrence of contiguous anomalies in areas affected by drought during the maximum biomass period suggests that the slope and curvature contain information on the impact of drought on vegetation. The difference in spatial patterns between the vegetation parameter anomalies and the soil moisture anomalies suggests that the impact of the soil moisture anomaly had a bigger impact on some vegetation types. The observed anomalies in slope are consistent with the interpretation of slope as an indicator of vegetation density. The increased soil moisture deficit reduces both the fresh biomass and the vegetation water content. The dynamics of the curvature provide insight into the dominant scattering mechanism, which in turn is determined by species abundance and the grass response to limited moisture availability.

\subsection{Nebraska Sand Hills}

The Nebraska Sand Hills ecoregion is the largest grass-covered sand dune area in the western hemisphere and is regarded as one of the most important groundwater-recharge areas for the Ogallala aquifer [44, 45]. The region is almost $85 \%$ intact natural grasslands [46]. The upland prairies are dominated by $\mathrm{C}_{4}$ grasses, namely sand bluestem (Andropogon hallii Vitman), little bluestem [Schizachyrium scoparium (Michx.) Nash], prairie sandreed [Calamovilfa longifolia (Hook) Scribn.] and switchgrass (Panicum virga- tum L.) [4]. These $\mathrm{C}_{4}$ grasses are better-adapted to periodic drought than other plant types. The following results are spatially averaged across all grid points between $(41.5 \mathrm{~N}$, $101 \mathrm{~W})$ and $(42.5 \mathrm{~N}, 102 \mathrm{~W})$.

Figure 6(d) shows a time series of the cumulative percent area of the state of Nebraska experiencing each of the five levels of drought intensity. Less than $20 \%$ of the state was affected by the D2 conditions in 2007. Figure6(a) suggests the drought was primarily in western Nebraska including the Nebraska Sand Hills. 


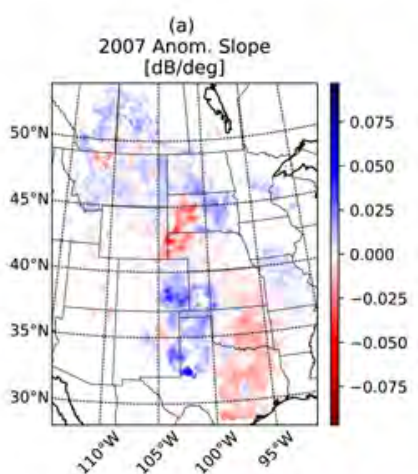

(c)
2011 Anom. Slope

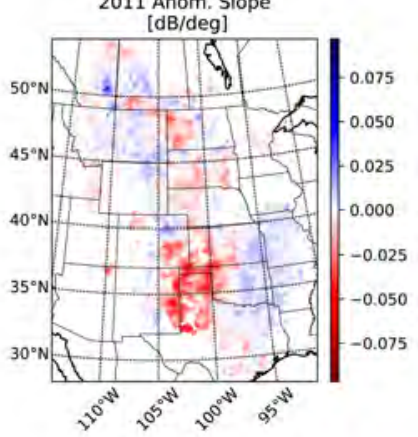

(e)

2012 Anom. Slope

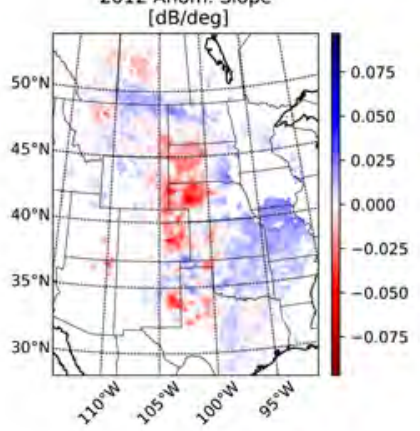

(b)

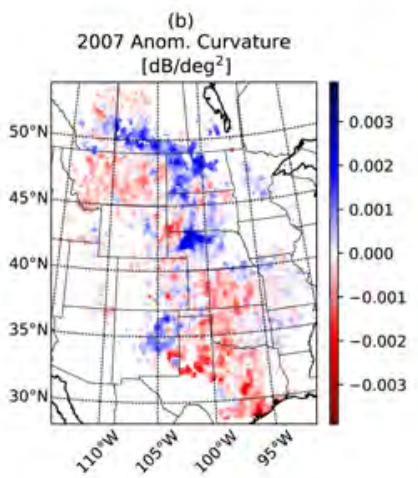

(d)

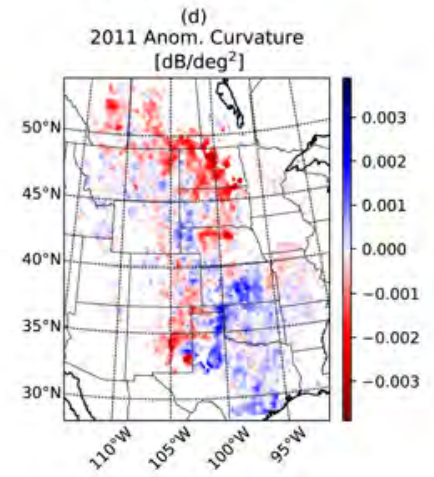

2012 Anom. Curvature

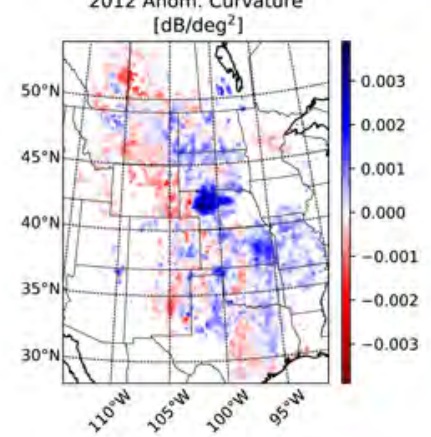

Figure 14: Anomalies in slope (left) and curvature (right) values during the biomass peak (DOY 170-220). Values are determined using all data (i.e. including descending and ascending overpass data). 
(a)

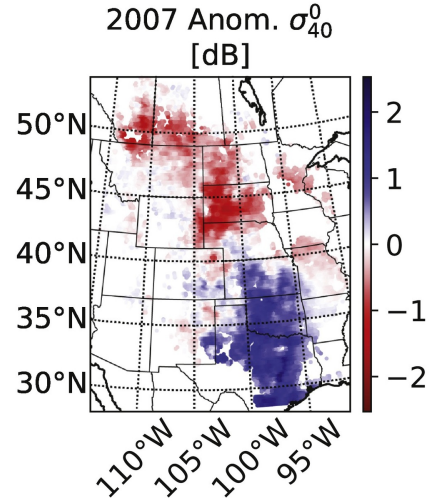

(c)

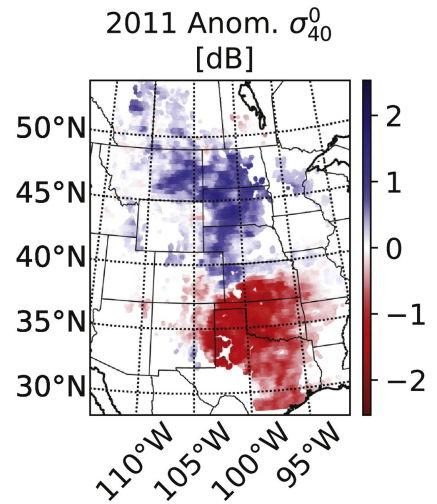

(e)

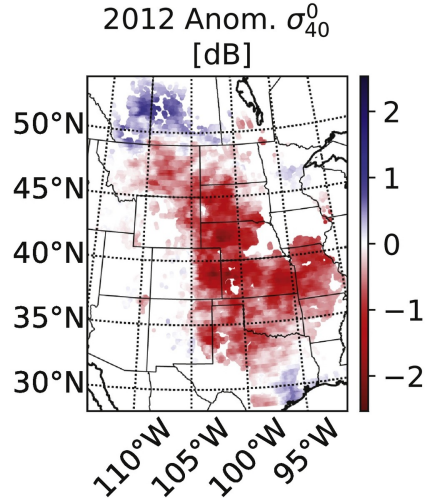

(b)

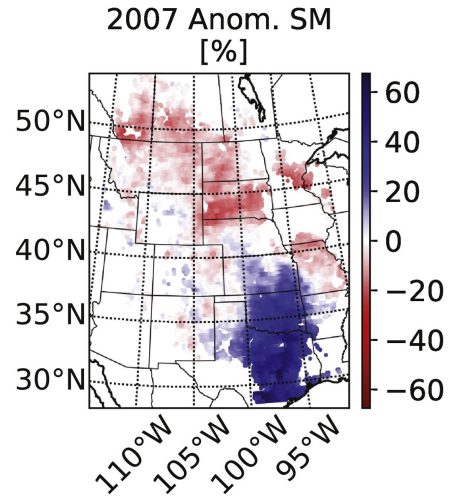

(d)

2011 Anom. SM

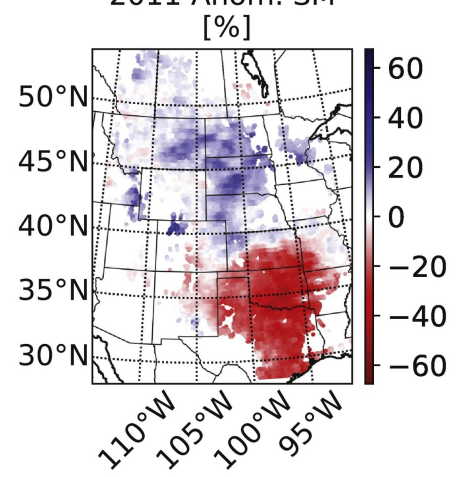

(f)

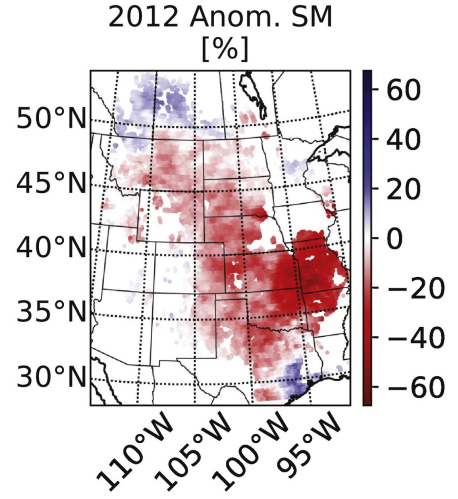

Figure 15: Anomalies in $\sigma_{40}^{\circ}$ (left) and soil moisture (right) values during the biomass peak (DOY 170-220) in 2007, 2011, and 2012. Values are determined using all data (i.e. including descending and ascending overpass data). 
The rapid escalation in severity, and duration of the 2012-2013 drought is very striking. The spring rains of 2013 succeeded in lowering the intensity, but even by the summer of 2013 , more than $60 \%$ of the state was still experiencing D2 conditions.

Figure 16 shows the seasonal climatology (a)-(d) and the time series of anomalies $(\mathrm{e})-(\mathrm{h})$ for the vegetation parameters, $\sigma_{40}^{\circ}$ and soil moisture in the Nebraska Sand Hills. Winter and summer slope values are beyond the range observed in the aggregated grassland ROIs, and curvature is higher than that observed in any of the ROIs. The seasonal cycles of curvature, $\sigma_{40}^{\circ}$ and soil moisture are marketdly different than those observed in Figure 4. Soil is very dry during November/December, and the maximum soil moisture occurs in the Spring. $\sigma_{40}^{\circ}$ therefore has a winter minimum, and a summer maximum which coincides with the maximum slope values. This suggests that vegetation makes a significant contribution to total backscatter during the summer months.

The severity of the 2012-2013 soil moisture anomaly and its duration are apparent in Figure 16(h). An initial negative soil moisture anomaly in soil moisture occurs in late 2011-January 2012, though it is dissipated by precipitation in February-April. A significant anomaly, up to 20\%, initiated in the summer of 2012 persists through to January 2013. This anomaly is also very clear in the $\sigma_{40}^{\circ}$ data, where backscatter is up to $2 \mathrm{~dB}$ lower than usual. At the start of 2012, slope is higher than normal, though it starts to decrease abruptly in early June and this negative anomaly persists until June 2013. A large positive curvature anomaly persists from April to October 2012, with the maximum deviation from climatology $\left(0.0035 \mathrm{~dB} / \mathrm{deg}^{2}\right)$ occurring at the start of August. The asynchronous anomalies in slope and curvature produce the unexpected combination of a negative slope anomaly with a positive curvature anomaly during the maximum biomass period. This suggests that vegetation density is less than normal, but a stronger dominance of the direct scattering from the canopy over the ground-bounce term. Given the low water-holding capacity of the sandy soils, and the magnitude of the soil moisture and $\sigma_{40}^{\circ}$ anomalies, it seems plausible that the soils were completely dry and therefore contributed less 

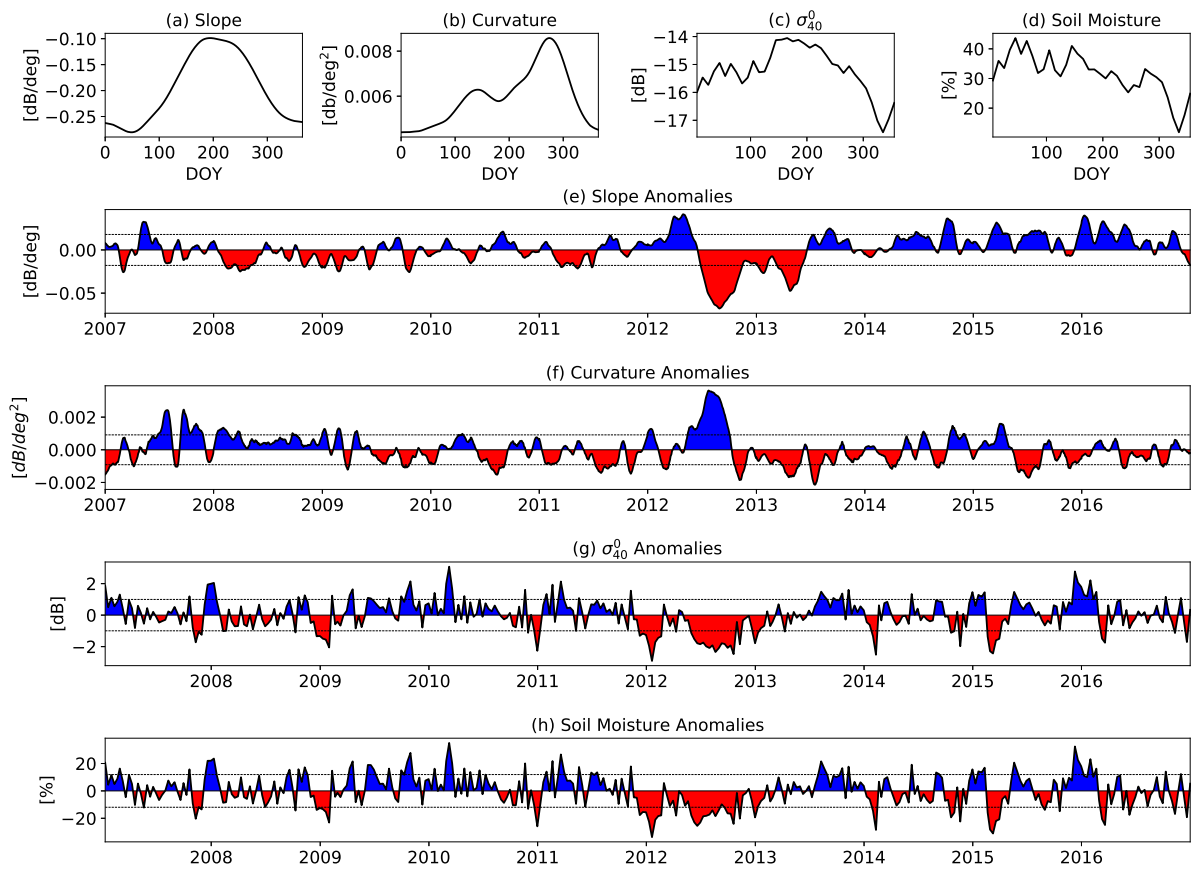

Figure 16: Climatology of slope(a), curvature (b), normalized backscatter (c) and soil moisture (d) values averaged across the Nebraska Sand Hills, followed by the time series of anomalies observed in the same quantities (e)-(h) during the study period.

to total backscatter than the vegetation. The $\mathrm{C}_{4}$ grasses of the upland prairie in the Nebraska sandhills are better adapted to withstand periodic drought than other plant types. Stomatal closure and leaf rolling in these grasses reduces transpiration and prolongs survival to drought [47]. This supports the idea that moisture was present in the vegetation long after the soil surface dried, allowing direct scattering to dominate over ground-bounce term. 


\section{Conclusions}

The first ten years of ASCAT backscatter data from Metop-A were analyzed to characterize the spatial and temporal variability in the vegetation parameters of the TUW SMR approach. Seasonal climatology, spatial patterns and interannual variability in the slope vary between grassland cover types, reflecting variations in the soil moisture availability and growing season length. While the seasonal cycle of the slope support its interpretation in the TUW SMR approach as a measure of "vegetation density", it would be useful to be able to relate this directly to biomass or vegetation water content.

Until now, the TUW SMR curvature parameter has not been explored as a source of information about vegetation. Results presented here demonstrate that curvature is clearly influenced by vegetation phenology, with significant variations occurring at the start and end of the growing season. Its seasonal cycle varies considerably across the different land cover types, but does not appear to have a simple relationship with slope. Results are consistent with the idea that the curvature is a measure of the relative dominance of direct scattering from vertical vegetation constituents over a ground-bounce contribution. This has been observed in wheat and barley that, similar to many grasses, have a predominantly vertical structure. The relative dominance of these two scattering mechanisms is influenced by the total vegetation water content, its vertical distribution within the vegetation, and the geometry of the vegetation constituents. The seasonal dynamics, and anomalies observed in the curvature values during drought conditions suggest that the curvature may yield valuable insight into the drought response of vegetation in grasslands. The potential value of the curvature values as a source of information about the vegetation in other land cover types needs to be further investigated.

The drought events in 2011 and 2012 resulted in extensive negative $\sigma_{40}^{\circ}$ and soil moisture anomalies during the maximum biomass period. The impact on slope and curvature was more spatially heterogeneous. However, contiguous anomalies were observed in locations where the severity and persistence of the 
drought were enough to impact vegetation. A time series of observations from the Nebraska Sand Hills confirmed that prolonged drought conditions, indicated by soil moisture anomalies, resulted in lagged anomalies in both the slope and curvature. This suggests that anomalies in these vegetation parameters might be useful to detect when a soil moisture anomaly is severe enough that it impacts the vegetation.

The results presented here suggest that considering the slope and curvature dynamics in combination with the backscatter itself could yield valuable insights into canopy water dynamics. The incidence angle dependence of backscatter depends on the relative dominance of surface, volume and multiple scattering which, in turn, depend on vegetation structure, total water content and the vertical distribution of moisture within the vegetation. The dynamics of slope and curvature contain information on how these quantities are changing in time. The vegetation parameters could therefore be useful for attributing backscatter variations to moisture or structural changes associated with vegetation phenology or environmental stress.

It is particularly noteworthy that diurnal differences have been identified in the vegetation parameters. This shines a new light on previous studies in which diurnal differences in ASCAT observations were detected. Friesen et al. [13] and [48] analyzed data processed using WARP5.0, in which long-term climatological values of vegetation parameters were used to normalize backscatter to the reference angle of $40^{\circ}$. Using the new approach of Melzer [19], not only can the interannual variability be taken into account, but vegetation parameters can be calculated separately for the ascending and descending overpasses. Using these distinct parameter values, it is possible to take into account changes in the relative importance of different scattering mechanisms between the ascending and descending overpasses. The value of the split (descending/ascending) vegetation parameters is expected to be greatest in cover types in which total backscatter is influenced by a combination of soil surface and vegetation contributions, e.g. grasslands, savannas. Grasslands proved particularly interesting in this regard because their structure plays a role in the relative dominance of the soil and 
vegetation contributions.

In order to relate ASCAT observations to canopy water dynamics, the overpass time needs to be considered from a plant-physiological point of view. Metop's 9:30 AM (local) overpass time is advantageous in the sense that dew should be less than pre-dawn values. However, it also means that vegetated surfaces are observed after several hours of evapotranspiration. The impact on the moisture content of individual constituents (leaves, branches, trunk/stalk) and total vegetation water content varies considerably by vegetation and climate type. This underscores the need for an improved understanding of the vertical distribution of moisture within vegetation, its daily cycle, how it varies in response to environmental stress and how it influences total backscatter.

Dynamic estimation of the vegetation parameters will guide improvements in the TUW SMR approach for retrieving soil moisture from ASCAT observations. Furthermore, results presented here suggest that the ability to dynamically estimate the slope and curvature of the $\sigma^{\circ}-\theta$ relationship may yield new insights into vegetation dynamics using C-band scatterometry. This offers many opportunities to use the current archive of ASCAT data for vegetation monitoring. This study also highlights the need for improved understanding of the influence of soil-vegetation water dynamics on scattering mechanisms. This would benefit exploitation of data from both ASCAT on-board the series of Metop satellites and the next generation instrument SCA on-board Metop-SG.

\section{Acknowledgements}

This work was supported by a Visiting Scientist activity funded under ESA Climate Change Initiative Phase 2 Soil Moisture Project (ESA Contract No. 4000112226/14/I-NB). The U.S. Drought Monitor is jointly produced by the National Drought Mitigation Center at the University of Nebraska-Lincoln, the United States Department of Agriculture, and the National Oceanic and Atmospheric Administration. Maps and time series data are courtesy of NDMC-UNL and were obtained from http://droughtmonitor.unl.edu. 


\section{References}

[1] V. R. Wismann, K. Boehnke, C. Schmullius, Monitoring ecological dynamics in Africa with the ERS-1 scatterometer, in: Geoscience and Remote Sensing Symposium, 1995. IGARSS'95.'Quantitative Remote Sensing for Science and Applications', International, Vol. 2, IEEE, 1995, pp. 15231525 .

[2] P. L. Frison, E. Mougin, P. Hiernaux, Observations and Interpretation of Seasonal ERS-1 Wind Scatterometer Data over Northern Sahel (Mali), Remote Sensing of Environment 63 (3) (1998) 233-242. doi:10.1016/ S0034-4257(97)00137-5

[3] I. H. Woodhouse, J. J. v. d. Sanden, D. H. Hoekman, Scatterometer observations of seasonal backscatter variation over tropical rain forest, IEEE Transactions on Geoscience and Remote Sensing 37 (2) (1999) 859-861. doi:10.1109/36.752204.

[4] E. P. W. Attema, The Active Microwave Instrument on-board the ERS-1 satellite, Proceedings of the IEEE 79 (6) (1991) 791-799. doi:10.1109/5. 90158

[5] W. Wagner, S. Hahn, R. Kidd, T. Melzer, Z. Bartalis, S. Hasenauer, J. Figa-Saldaña, P. de Rosnay, A. Jann, S. Schneider, J. Komma, G. Kubu, K. Brugger, C. Aubrecht, J. Zger, U. Gangkofner, S. Kienberger, L. Brocca, Y. Wang, G. Blschl, J. Eitzinger, K. Steinnocher, P. Zeil, F. Rubel, The ASCAT Soil Moisture Product: A Review of its Specifications, Validation Results, and Emerging Applications, Meteorologische Zeitschrift 22 (1) (2013) 5-33. doi:10.1127/0941-2948/2013/0399.

[6] A. Stoffelen, S. Aaboe, J. C. Calvet, J. Cotton, G. D. Chiara, J. FigaSaldaña, A. A. Mouche, M. Portabella, K. Scipal, W. Wagner, Scientific Developments and the EPS-SG Scatterometer, IEEE Journal of Selected Topics in Applied Earth Observations and Remote Sensing 10 (5) (2017) 2086-2097. doi:10.1109/JSTARS.2017.2696424. 
[7] L. Jarlan, E. Mougin, P. L. Frison, P. Mazzega, P. Hiernaux, Analysis of ERS wind scatterometer time series over Sahel (Mali), Remote Sensing of Environment 81 (23) (2002) 404-415. doi:10.1016/S0034-4257(02) 00015-9

[8] L. Jarlan, P. Mazzega, E. Mougin, F. Lavenu, G. Marty, P. Frison, P. Hiernaux, Mapping of Sahelian vegetation parameters from ERS scatterometer data with an evolution strategies algorithm, Remote Sensing of Environment 87 (1) (2003) 72-84. doi:10.1016/S0034-4257(03)00164-0.

[9] S. Zine, L. Jarlan, P. Frison, E. , P. Hiernaux, J. Rudant, Land surface parameter monitoring with ERS scatterometer data over the Sahel: A comparison between agro-pastoral and pastoral areas, Remote Sensing of Environment 96 (3-4) (2005) 438-452. doi:10.1016/j.rse.2005.04.012

[10] I. H. Woodhouse, D. H. Hoekman, Determining land-surface parameters from the ERS wind scatterometer, Geoscience and Remote Sensing, IEEE Transactions on 38 (1) (2000) 126-140.

[11] I. H. Woodhouse, D. H. Hoekman, A model-based determination of soil moisture trends in Spain with the ERS-scatterometer, IEEE Transactions on Geoscience and Remote Sensing 38 (4) (2000) 1783-1793. doi:10.1109/ 36.851762 .

[12] C. Fatras, F. Frappart, E. Mougin, P. L. Frison, G. Faye, P. Borderies, L. Jarlan, Spaceborne altimetry and scatterometry backscattering signatures at C- and Ku-bands over West Africa, Remote Sensing of Environment 159 (Supplement C) (2015) 117-133. doi:10.1016/j.rse.2014.12. 005 .

[13] J. Friesen, H. C. Winsemius, R. Beck, K. Scipal, W. Wagner, N. Van De Giesen, Spatial and seasonal patterns of diurnal differences in ERS Scatterometer soil moisture data in the Volta Basin, West Africa, IAHS PUBLICATION 316 (2007) 47. 
[14] J. Friesen, Regional vegetation water effects on satellite soil moisture estimations for West Africa, Ph.D. thesis, Zentrum für Entwicklungsforschung ZEF, Bonn, Germany (2008).

[15] R. Schroeder, K. C. McDonald, M. Azarderakhsh, R. Zimmermann, ASCAT MetOp-A diurnal backscatter observations of recent vegetation drought patterns over the contiguous U.S.: An assessment of spatial extent and relationship with precipitation and crop yield, Remote Sensing of Environment 177 (2016) 153-159. doi:10.1016/j.rse.2016.01.008.

[16] T. van Emmerik, S. Steele-Dunne, A. Paget, R. S. Oliveira, P. R. L. Bittencourt, F. d. V. Barros, N. van de Giesen, Water stress detection in the Amazon using radar, Geophysical Research Letters 44 (13) (2017) 2017GL073747. doi:10.1002/2017GL073747.

[17] A. G. Konings, Y. Yu, L. Xu, Y. Yang, D. S. Schimel, S. S. Saatchi, Active microwave observations of diurnal and seasonal variations of canopy water content across the humid African tropical forests, Geophysical Research Letters 44 (5) (2017) 2016GL072388. doi:10.1002/2016GL072388.

[18] V. Naeimi, K. Scipal, Z. Bartalis, S. Hasenauer, W. Wagner, An Improved Soil Moisture Retrieval Algorithm for ERS and METOP Scatterometer Observations, IEEE Transactions on Geoscience and Remote Sensing 47 (7) (2009) 1999-2013. doi:10.1109/TGRS.2008.2011617.

[19] T. Metzler, Vegetation modelling in warp 6.0, in: Proc. EUMETSAT Meteorological Satellite Conf., Vienna, Austria, 2013, pp. 1-7.

[20] M. Vreugdenhil, S. Hahn, T. Melzer, B. Bauer-Marschallinger, C. Reimer, W. A. Dorigo, W. Wagner, Assessing vegetation dynamics over mainland Australia with Metop ASCAT, IEEE Journal of Selected Topics in Applied Earth Observations and Remote Sensing 10 (5) (2017) 2240-2248.

[21] W. Wagner, G. Lemoine, M. Borgeaud, H. Rott, A study of vegetation 
cover effects on ERS scatterometer data, IEEE Transactions on Geoscience and Remote Sensing 37 (2) (1999) 938-948. doi:10.1109/36.752212.

[22] W. Wagner, G. Lemoine, H. Rott, A method for estimating soil moisture from ERS scatterometer and soil data, Remote sensing of environment 70 (2) (1999) 191-207.

[23] W. Wagner, K. Scipal, C. Pathe, D. Gerten, W. Lucht, B. Rudolf, Evaluation of the agreement between the first global remotely sensed soil moisture data with model and precipitation data, Journal of Geophysical Research: Atmospheres 108 (D19) (2003) 4611. doi:10.1029/2003JD003663.

[24] Z. Bartalis, W. Wagner, V. Naeimi, S. Hasenauer, K. Scipal, H. Bonekamp, J. Figa, C. Anderson, Initial soil moisture retrievals from the METOP-A Advanced Scatterometer (ASCAT), Geophysical Research Letters 34 (20) (2007) L20401. doi:10.1029/2007GL031088.

[25] L. Brocca, W. T. Crow, L. Ciabatta, C. Massari, P. d. Rosnay, M. Enenkel, S. Hahn, G. Amarnath, S. Camici, A. Tarpanelli, W. Wagner, A Review of the Applications of ASCAT Soil Moisture Products, IEEE Journal of Selected Topics in Applied Earth Observations and Remote Sensing 10 (5) (2017) 2285-2306. doi:10.1109/JSTARS.2017.2651140.

[26] S. C. Steele-Dunne, H. McNairn, A. Monsivais-Huertero, J. Judge, P. W. Liu, K. Papathanassiou, Radar Remote Sensing of Agricultural Canopies: A Review, IEEE Journal of Selected Topics in Applied Earth Observations and Remote Sensing PP (99) (2017) 1-25. doi:10.1109/JSTARS. 2016. 2639043

[27] W. Dorigo, A. Gruber, R. De Jeu, W. Wagner, T. Stacke, A. Loew, C. Albergel, L. Brocca, D. Chung, R. Parinussa, R. Kidd, Evaluation of the ESA CCI soil moisture product using ground-based observations, Remote Sensing of Environment 162 (2015) 380-395. doi:10.1016/j.rse.2014. 07.023 
[28] M. Zribi, O. Taconet, S. Le Hgarat-Mascle, D. Vidal-Madjar, C. Emblanch, C. Loumagne, M. Normand, Backscattering behavior and simulation comparison over bare soils using SIR-C/X-SAR and ERASME 1994 data over Orgeval, Remote Sensing of Environment 59 (2) (1997) 256-266. doi:10.1016/S0034-4257(96)00158-7.

[29] W. Wagner, J. Noll, M. Borgeaud, H. Rott, Monitoring soil moisture over the Canadian Prairies with the ERS scatterometer, IEEE Transactions on Geoscience and Remote Sensing 37 (1) (1999) 206-216. doi:10.1109/36. 739155

[30] S. Hahn, C. Reimer, M. Vreugdenhil, T. Melzer, W. Wagner, Dynamic Characterization of the Incidence Angle Dependence of Backscatter Using Metop ASCAT, IEEE Journal of Selected Topics in Applied Earth Observations and Remote Sensing PP (99) (2017) 1-12. doi:10.1109/JSTARS. 2016.2628523

[31] V. Naeimi, Z. Bartalis, W. Wagner, ASCAT Soil Moisture: An Assessment of the Data Quality and Consistency with the ERS Scatterometer Heritage, Journal of Hydrometeorology 10 (2) (2009) 555-563. doi: 10.1175/2008JHM1051.1.

[32] G. Kirches, C. Brockmann, M. Boettcher, M. Peters, S. Bontemps, C. Lamarche, M. Schlerf, M. Santoro, P. Defourny, Land cover cci product user guide: Version 2, ESA Public Document CCI-LC-PUG (2) (2014) 4.

[33] D. M. Olson, E. Dinerstein, E. D. Wikramanayake, N. D. Burgess, G. V. N. Powell, E. C. Underwood, J. A. D’amico, I. Itoua, H. E. Strand, J. C. Morrison, C. J. Loucks, T. F. Allnutt, T. H. Ricketts, Y. Kura, J. F. Lamoreux, W. W. Wettengel, P. Hedao, K. R. Kassem, Terrestrial Ecoregions of the World: A New Map of Life on Earth, BioScience 51 (11) (2001) 933-938. doi:10.1641/0006-3568(2001)051[0933:TEOTWA]2.0.C0;2.

[34] M. C. Peel, B. L. Finlayson, T. A. McMahon, Updated world map of the 
Kp̈pen-Geiger climate classification, Hydrology and earth system sciences discussions 4 (2) (2007) 439-473.

[35] E. Dinerstein, D. Olson, A. Joshi, C. Vynne, N. D. Burgess, E. Wikramanayake, N. Hahn, S. Palminteri, P. Hedao, R. Noss, M. Hansen, H. Locke, E. C. Ellis, B. Jones, C. V. Barber, R. Hayes, C. Kormos, V. Martin, E. Crist, W. Sechrest, L. Price, J. E. M. Baillie, D. Weeden, K. Suckling, C. Davis, N. Sizer, R. Moore, D. Thau, T. Birch, P. Potapov, S. Turubanova, A. Tyukavina, N. de Souza, L. Pintea, J. C. Brito, O. A. Llewellyn, A. G. Miller, A. Patzelt, S. A. Ghazanfar, J. Timberlake, H. Klser, Y. Shennan-Farpn, R. Kindt, J.-P. B. Lilles, P. van Breugel, L. Graudal, M. Voge, K. F. Al-Shammari, M. Saleem, An EcoregionBased Approach to Protecting Half the Terrestrial Realm, BioScience 67 (6) (2017) 534-545. doi:10.1093/biosci/bix014.

[36] C. Reimer, Calibration of space-borne scatterometers: Towards a consistent climate data record for soil moisture retrieval (MSc. thesis), Department of Geodesy and Geoinformation, Vienna University of Technology,Vienna, Austria. (7 2014).

[37] Z. Bartalis, K. Scipal, W. Wagner, Azimuthal anisotropy of scatterometer measurements over land, IEEE Transactions on Geoscience and Remote Sensing 44 (8) (2006) 2083-2092. doi:10.1109/TGRS.2006.872084.

[38] J. Figa-Saldaña, J. J. Wilson, E. Attema, R. Gelsthorpe, M. R. Drinkwater, A. Stoffelen, The advanced scatterometer (ASCAT) on the meteorological operational (MetOp) platform: A follow on for European wind scatterometers, Canadian Journal of Remote Sensing 28 (3) (2002) 404-412. doi:10.5589/m02-035

[39] F. T. Ulaby, R. K. Moore, A. K. Fung, Microwave remote sensing active and passive-volume III: from theory to applications, Artech House, Inc, 1986. 
[40] S. Bakhtiari, R. Zoughi, A model for backscattering characteristics of tall prairie grass canopies at microwave frequencies, Remote Sensing of Environment 36 (2) (1991) 137-147. doi:10.1016/0034-4257(91)90036-6.

[41] F. Mattia, T. L. Toan, G. Picard, F. I. Posa, A. D'Alessio, C. Notarnicola, A. M. Gatti, M. Rinaldi, G. Satalino, G. Pasquariello, Multitemporal C-band radar measurements on wheat fields, IEEE Transactions on Geoscience and Remote Sensing 41 (7) (2003) 1551-1560. doi: 10.1109/TGRS. 2003.813531

[42] J. M. Stiles, K. Sarabandi, F. T. Ulaby, Electromagnetic scattering from grassland. II. Measurement and modeling results, IEEE Transactions on Geoscience and Remote Sensing 38 (1) (2000) 349-356. doi:10.1109/36. 823930

[43] C. Wang, E. R. Hunt, L. Zhang, H. Guo, Phenology-assisted classification of C3 and C4 grasses in the U.S. Great Plains and their climate dependency with MODIS time series, Remote Sensing of Environment 138 (Supplement C) (2013) 90-101. doi:10.1016/j.rse.2013.07.025.

[44] A. S. Bleed, C. Flowerday, An atlas of the Sand Hills, Conservation and Survey Division, Institute of Agriculture and Natural Resources, University of Nebraska-Lincoln, 1990.

[45] J. Szilagyi, V. A. Zlotnik, J. B. Gates, J. Jozsa, Mapping mean annual groundwater recharge in the Nebraska Sand Hills, USA, Hydrogeology Journal 19 (8) (2011) 1503-1513. doi:10.1007/s10040-011-0769-3.

[46] Nebraska Sand Hills mixed grasslands | Ecoregions | WWF URL https://www.worldwildlife.org/ecoregions/na0809

[47] T. Awada, L. E. Moser, W. H. Schacht, P. E. Reece, Stomatal variability of native warm-season grasses from the Nebraska Sandhills, Canadian journal of plant science 82 (2) (2002) 349-355. 
826

[48] J. Friesen, S. C. Steele-Dunne, N. van de Giesen, Diurnal Differences in Global ERS Scatterometer Backscatter Observations of the Land Surface, IEEE Transactions on Geoscience and Remote Sensing 50 (7) (2012) 25952602. doi:10.1109/TGRS.2012.2193889. 